\title{
Toxicity assessment of water-accommodated fractions from two different oils using a zebrafish (Danio rerio) embryo- larval bioassay with a multilevel approach
}

\author{
Perrichon Prescilla ${ }^{1,2,{ }^{*}}$, Le Menach Karyn ${ }^{3}$, Akcha Farida ${ }^{1}$, Cachot Jerome ${ }^{3}$, Budzinski Helene ${ }^{3}$, \\ Bustamante Paco ${ }^{2}$
}

${ }^{1}$ IFREMER, Lab Biogeochim \& Ecotoxicol, Lhoumeau Nantes, France.

2 Univ La Rochelle, CNRS, Littoral Environm \& Soc LIENSs, UMRi 7266, 2 Rue Olympe Gouges, F17042 La Rochelle 01, France.

${ }^{3}$ Univ Bordeaux, UMR EPOC CNRS 5805, Ave Fac, F-33405 Talence, France.

*Corresponding author : Prescilla Perrichon, email address : prescilla.perrichon@gmail.com

\begin{abstract}
:
Petroleum compounds from chronic discharges and oil spills represent an important source of environmental pollution. To better understand the deleterious effects of these compounds, the toxicity of water-accommodated fractions (WAF) from two different oils (brut Arabian Light and Erika heavy fuel oils) were used in this study. Zebrafish embryos (Danio rerio) were exposed during $96 \mathrm{~h}$ at three WAF concentrations (1, 10 and $100 \%$ for Arabian Light and 10,50 and 100\% for Erika) in order to cover a wide range of polycyclic aromatic hydrocarbon (PAH) concentrations, representative of the levels found after environmental oil spills. Several endpoints were recorded at different levels of biological organization, including lethal endpoints, morphological abnormalities, photomotor behavioral responses, cardiac activity, DNA damage and exposure level measurements (EROD activity, cyp1a and PAH metabolites). Neither morphological nor behavioral or physiological alterations were observed after exposure to Arabian Light fractions. In contrast, the Erika fractions led a high degree of toxicity in early life stages of zebrafish. Despite of defense mechanisms induced by oil, acute toxic effects have been recorded including mortality, delayed hatching, high rates of developmental abnormalities, disrupted locomotor activity and cardiac failures at the highest PAH concentrations $\left(\Sigma\right.$ TPAHs $\left.=257,029 \pm 47,231 \mathrm{ng} \cdot \mathrm{L}^{-1}\right)$. Such differences in toxicity are likely related to the oil composition. The use of developing zebrafish is a good tool to identify wide range of detrimental effects and elucidate their underlying foundations. Our work highlights once more, the cardiotoxic action (and potentially neurotoxic) of petroleum-related PAHs.
\end{abstract}




\section{Graphical abstract}

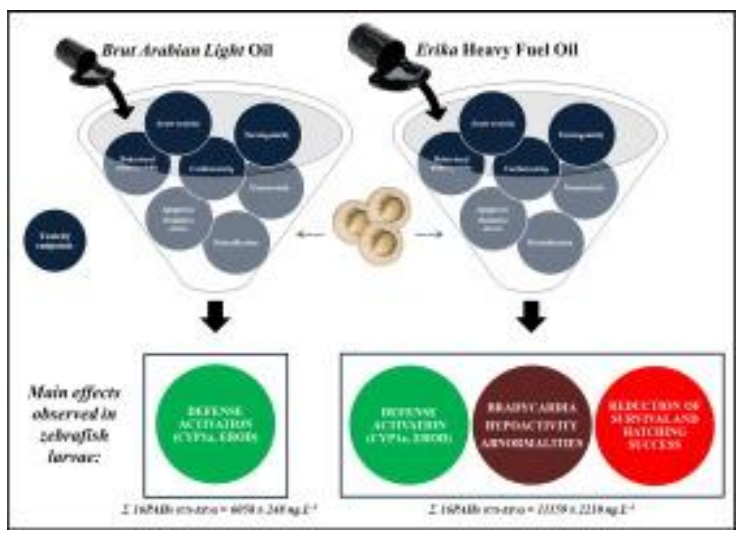

\section{Highlights}

The toxicity of dissolved fractions from two different oils: Brut Arabian Light and Erika fuel oil, was examined in early life stages of zebrafish. A phenotypic map of the deleterious effects of these both oils-derived polycyclic aromatic hydrocarbons is provided. Two vital functions are primarily affected by oil: the swimming and cardiac performances. Critical impact on the vital functions might have disastrous consequences for survival population.

Keywords : Zebrafish embryos, Oil exposure, Teratogenicity, Swimming performance, Bradycardia, Detoxification pathway

\section{Abbreviations}

- BAL, brut Arabian Light,

- ELS, early life stage;

- EROD, ethoxyresorufin-O-deethylase;

- hpf, hours post-fertilization;

- HFO, heavy fuel oil;

- HMW, high molecular weight;

- hpf, hours post-fertilization;

- LMW, low molecular weight;

- PAHs, polycyclic aromatic hydrocarbons;

- PMR, photomotor response;

- RT-PCR, Real-Time Polymerase Chain Reaction;

- WAF, water-accommodated fractions 


\section{Introduction}

Oil pollution by liquid petroleum (crude oil and refined products) represents an important source of pollution in marine ecosystems. Petroleum compounds originating from oil spills and chronic discharges from maritime transport (oiled-ballast water, cargo washing, wreckage), offshore exploitation (drilling operations) and natural seepage may lead to disastrous ecological consequences when released into the environment (GESAMP 2007; GESAMP 1993). The risk assessment of petroleum discharges in aquatic ecosystems remains complicated as they usually occur as complex mixtures of organic compounds. Crude oils are composed of tens of thousands of compounds with 75\% are hydrocarbons, including polycyclic aromatic hydrocarbons (PAHs) (OSPAR 2004). These persistent pollutants exhibit different levels of toxicity and induce different kinds of effects in aquatic organisms (Incardona et al. 2004; Lee and Anderson 2005) depending on their physico-chemical properties and the speed of microbial transformation (Heintz et al. 1999). The low molecular weight (LMW) PAHs with 2 to 3 rings are usually rapidly dispersed in the water column $\left(\log \mathrm{K}_{\mathrm{ow}}<4\right)$ after oil spills and are less persistent in the 
environment because of their high volatility. In contrast, high molecular weight (HMW) PAHs (e.g., 3 rings and more) are more hydrophobic $\left(\log \mathrm{K}_{\mathrm{ow}}>4\right)$ and therefore less water soluble and more persistent (Black et al. 1983; Rice et al. 2001). Oil toxicity is mostly related to the aromatic fraction made of both LMW and HMW PAHs. As well, dissolved fractions of petroleum appear to be more bioavailable to aquatic organisms.

Oil-derived PAH contamination is responsible for notable environmental damage, exhibiting variable levels of toxicity (from the molecular to population levels) (NRC 2003). Fish early-life stages (ELS) are known to be particularly sensitive to these compounds (Lammer et al. 2009) that can dramatically impact the survival and recruitment of fish populations (Heintz et al. 2000; McGurk and Brown 1996; Muhling et al. 2012). DNA damage (strand breakage and adduct formation), mutations and tumors have been frequently observed in marine (Le Dû-Lacoste et al. 2013; Wessel et al. 2012) and freshwater (Cachot et al. 2007) fish species exposed to PAHcontaminated sediment and dissolved fractions of oils. Numerous studies have identified physiological disruptions, including blood disorders and cardiac defects after exposure to PAHs mixtures. Reduction of heart rate was found in the embryonic stages of Inland silversides fish (Menidia beryllina) after being exposed to water-soluble fractions of Alaska North Slope crude oil (Middaugh et al. 1996). Heart contraction disruptions were recorded in cardiomyocytes of juvenile bluefin and yellowfin tunas after exposure to Deepwater Horizon crude oil (Brette et al. 2014). With a similar oil, Incardona et al. (2014) have demonstrated serious defects in heart development with circulatory disruption and irregular atrial arrhythmia in three pelagic fish embryos: bluefin tuna (Thunnus thynnus), yellowfin tuna (Thunnus albacares) and amberjacks (Seriola dumerili). For several years, these same authors have also documented cardiac detriments in blood circulation (anemia, atrial arrhythmia) and morphological defects (edemas) following exposure to PAH mixtures from crude oil in zebrafish (Danio rerio) and Pacific 
herring (Clupea pallasi) (Incardona et al., 2013, 2012, 2009). Various investigations have also found dissolved fractions of oil (Ekofish crude oil) responsible for modifying the swimming and feeding behavior, with a significant reduction in the ability to capture prey, in the early larval stages of cod (Tilseth et al. 1984). At larger biological scales, crude oil and refined products have been described to alter the growth and cause anatomical malformations, including induction of edemas along with craniofacial and spinal abnormalities (Carls and Thedinga 2010; GonzálezDoncel et al. 2008; Hose et al. 1996; Kerambrun et al. 2012; Marty et al. 1997; Norcross et al. 1996; Pollino and Holdway 2002). Such disruptions in development stages that might be critical for later stages to ensure key physiological functioning (swimming, reproduction) compromise survival and maintenance of future generations. However, individuals exposed to oil-derived PAHs are not without defense and are able to metabolize much of the PAHs. Once assimiliated by the fish, PAHs are biotransformed into more water soluble metabolites through phase I biotransformation activities, predominantly catalyzed by cytochrome P450 1A (CYP1A) (Meador et al. 1995; Varanasi et al. 1985). Activation of these mechanisms via binding to the aryl hydrocarbon receptor (AhR) modulates the expression of a battery of genes involved in PAH biotransformation and detoxification pathways. However, such processes can produce metabolites potentially endowed with a higher toxicity than the native compounds they originate from, becoming highly toxic to fish embryo development and the organism's health.

The present study aimed to explore the toxic effects of two water-accommodated fractions (WAF) of varying compositions, from a light crude oil, brut Arabian Light (BAL) and a heavy fuel oil, Erika (HFO), on fish embryos and larvae. Zebrafish (Danio rerio) was selected as the test species because it is easily bred in the laboratory and eggs are available in high numbers throughout the years. The transparency of both chorion and larvae enable direct and non-invasive morphological observations. Using a multidisciplinary approach by coupling biology and 
chemistry, we monitored a wide range of fish toxic responses using phenotypic (survival, hatching success and abnormalities), behavioral (swimming activity), physiological (heartbeat) and cellular/subcellular markers (DNA damage, apoptosis and oxidative stress). In addition, the degree of exposure to PAHs was evaluated through the level of EROD activity, cypla induction and PAH metabolites in larvae.

\section{Materials and Methods}

2.1. Maintenance and egg production of zebrafish

Zebrafish (TU strain, Tübingen, Germany) were maintained according to Perrichon et al. (2014) in flow-through $10 \mathrm{~L}$ tanks in hatching groups of ten males and ten females. Maintenance standard conditions were characterized by the following parameters: $\mathrm{pH} 7.5 \pm 0.5$, conductivity $300 \pm 50 \mu \mathrm{S} . \mathrm{cm}^{-1}$, temperature $27 \pm 1{ }^{\circ} \mathrm{C}$ and an oxygen saturation $\geq 80 \%$. The photoperiod was

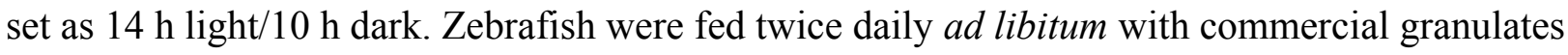
(INICIO Plus, BioMar, France) and live nauplius larvae of Artemias sp. (Ocean Nutrition, Belgium) once a day, occasionally supplemented with red sludge worms (Boschetto-Frozen fish food). Eggs were obtained by random pairwise mating of zebrafish. A couple of zebrafish was placed together in spawning boxes (AquaSchwarz, Germany) the evening before eggs were required. Spawning and fertilization took place within $30 \mathrm{~min}$ after the onset of light in the morning. Fertilized and normally developed eggs were then selected at 8 -cell stage ( $1 \mathrm{~h} 15$ postfertilization) from a mix of five spawns for the exposure.

\subsection{Experimental procedure}

\subsubsection{WAF preparation}

The water-accommodated fraction of oil was prepared according to guidelines established by the Chemical Response to Oil Spills - Ecological effects Research Forum (CROSSERF) (Singer et al. 2000). The WAF is a laboratory-prepared medium derived from low energy (no 
vortex) mixing of a poorly soluble test petroleum product which is essentially free of particles of bulk material (Aurand and Coelho 1996; Coelho and Aurand 1997). Two kinds of oils were used: an Arabian light crude oil (BAL 110) and an Erika heavy fuel oil (HFO, no 2). Center of Documentation, Research and Experimentation on Accidental Water Pollution (CEDRE) provided the both oils. Briefly, the WAF was prepared with $1.7 \mathrm{~L}$ of artificial water $(0.33 \mathrm{mM}$ $\mathrm{CaCl}_{2}, 0.33 \mathrm{mM} \mathrm{MgSO}_{4}, 5 \mathrm{mM} \mathrm{NaCl}$ and $0.17 \mathrm{mM} \mathrm{KCl}$ ) in $2 \mathrm{~L}$ glass aspirator bottle (equipped with a glass tap), closed by a lid to avoid the evaporation of light compounds. Oil concentrations introduced gently at the water surface were $103 \mathrm{mg}$ oil. $\mathrm{L}^{-1}$ water and $55 \mathrm{mg}$ oil. $\mathrm{L}^{-1}$ water for BAL and HFO oils respectively. These values were selected since they represent realistic concentrations after an oil spill release in static condition (Bado-Nilles et al., 2009; Tronczynski et al., 2004). A low mixing energy method (no vortexing) using magnetic stirrer was carried out for 24 hours in order to favor solubilization of the hydrosoluble molecules from the oil to the water column. Following 24 hours mixing period, WAF was settled 30 minutes before aliquot collection $(500 \mathrm{ml})$ in glass bottle. The sample was collected from the tap located at the bottom of the bottle. To maintain WAF equilibrium, procedure was set in an air-conditioned room $\left(21^{\circ} \mathrm{C}\right)$ and in the darkness. During exposure duration (96 h), WAF stock was stored at $4{ }^{\circ} \mathrm{C}$ in the dark to avoid compound degradation or photo-activation.

\subsubsection{Zebrafish exposure}

WAF solutions were diluted daily in three different concentrations with the artificial water. The WAF concentrations analyzed were $1 \%, 10 \%$ and $100 \%$ from BAL WAF stock solution and $10 \%, 50 \%$ and $100 \%$ from HFO WAF stock solution. A Control with only artificial water was also used. Exposures were carried out in five replicates in static conditions (Figure 1). 30 embryos (8-cell stage) and $10 \mathrm{~mL}$ of solution (WAF or artificial water) were placed into 20 $\mathrm{mL}$ glass dishes. Glass dishes were covered with Parafilm in order to prevent evaporation and incubated at $28 \pm 0.5^{\circ} \mathrm{C}$ for an exposure period of 96 hours. The photoperiod was similar to the rearing room. During exposure, WAF solutions and artificial water were renewed daily. Following exposure, surviving larvae were transferred to clean water until 15 days postfertilization (dpf). For the both oils, four consecutive experiments were done in order to analyze 
the all chemical and toxicity parameters and to test the experiment reproducibility. During experiments, zebrafish larvae were kept unfed.

This study was conducted with the approval of the Animal Care Committee of France under the official license of Marie-Laure Bégout (17-010).

\subsection{Chemicals analysis}

\subsubsection{PAHs analysis in water}

WAF samples were stored at $-20{ }^{\circ} \mathrm{C}$ before chemical analysis. The five replicates for each condition were pooled and water analyses were performed on two consecutive experiments for both oils. PAHs were extracted by SPME (Solid-Phase MicroExtraction) and then quantified by GC/MS (Gas Chromatography coupled Mass Spectrometer). During the whole exposure procedure, water (old and added new) was sampled every day in $10 \mathrm{~mL}$ SPME vials. Internal deuterated standard solutions (naphthalene- $\mathrm{d} 8$, acenaphtylene- $\mathrm{d} 8$, dibenzo $[\mathrm{b}, \mathrm{d}]$ thiophene- $\mathrm{d} 8$, acenaphtene- $\mathrm{d}_{10}$, fluorene- $\mathrm{d}_{10}$, phenanthrene- $\mathrm{d}_{10}$, anthracene- $\mathrm{d}_{10}$, fluoranthene- $\mathrm{d}_{10}$, pyrene- $\mathrm{d}_{10}$, chrysene-d $\mathrm{d}_{12}$, benzo[a] anthracene- $\mathrm{d}_{12}$, benzo[ $\left.\mathrm{b}+\mathrm{j}+\mathrm{k}\right]$ fluoranthene- $\mathrm{d}_{12}$, benzo[e]pyrene- $\mathrm{d}_{12}$, benzo[a]pyrene-d $\mathrm{d}_{12}$, perylene- $\mathrm{d}_{12}$, indeno[1,2,3cd]pyrene- $\mathrm{d}_{12}$, benzo[g,h,i]perylene- $\mathrm{d}_{12}$, dibenzo[a, $\mathrm{h}]+[\mathrm{a}, \mathrm{c}]$ anthracene- $\left.\mathrm{d}_{14}\right)$, diluted in ethanol, were added to $8 \mathrm{~mL}$ of water sample prior to extraction. Extractions were entirely automated with a Multipurpose Sampler (Gerstel ${ }^{\circledR}$ MPS2XL, Switzerland) using a PolyDiMethylSiloxan (PDMS) fiber (Supelco, Sigma-Aldrich, South Africa) following the procedure described by Kanan (2012). Briefly, the fiber $(100 \mu \mathrm{m})$ was immersed into the vial with $1 \mathrm{~h}$ stirring period at $250 \mathrm{rpm}$. After extraction, the fiber was thermally desorbed into the GC/MS system (Agilent GC 7890A/Agilent MSD 5975C, Agilent Technology, California) for $10 \mathrm{~min}$ at $270{ }^{\circ} \mathrm{C}$. A blank analysis was carried out to ensure the absence of contamination prior and during analysis.

The 40 detected compounds are listed in Table 1. Among these target compounds, 16 priority PAHs selected by the US EPA (Environmental Protection Agency), 2 additional parent PAHs (benzo[e]pyrene and perylene), 2 sulphurated aromatics (dibenzo[b,d]thiophene and 2,1dibenzonaphthothiophene) and 20 methylated-PAHs associated were identified. 


\subsubsection{PAH-metabolites analysis in larvae}

Larvae were sampled at the end of the exposure period (96 hpf) and stored at $-80{ }^{\circ} \mathrm{C}$ until used. Metabolites (hydroxyphenanthrenes, 3-hydroxyfluoranthene, 1-hydroxypyrene, 1hydroxychrysene, hydroxybenzo[a]pyrenes) were extracted from 50 pooled larvae and three replicates per WAF concentrations. Larvae were manually homogenized in 3-4 $\mathrm{mL}$ of sodium acetate buffer ( $\mathrm{pH}$ 5.0). An enzymatic deconjugation was performed during $16 \mathrm{~h}$ at $37^{\circ} \mathrm{C}$ after addition of beta-glucuronidase enzyme from Helix pomatia-2 ( $\geq 100000$ units. $\mathrm{mL}^{-1}$, SigmaAldrich, Germany) using methods adapted to Mazéas and Budzinski (2005). Prior to PAHmetabolites extraction, internal standard solutions (i.e. 1-hydroxypyrene-d9) were added to samples. Metabolites were extracted by Solid-Phase Extraction (SPE) procedure using octadecyl cartridge (500 mg, $3 \mathrm{cc}$, Bakerbond $\mathrm{C}_{18} \mathrm{SPE}$ ) and eluted with 100\% methanol solvent. After reconcentration of organic extracts with gas nitrogen, samples were purified by SPE using aminocolumn (500 mg, 3 cc, Supelco $\mathrm{NH}_{2}$-SPE) and eluted with dicholoromethane/methanol solution $(80 / 20, v / v)$. After another re-concentration step with gas nitrogen, PAH-metabolites extracts were analyzed by Liquid Chromatography coupled to tandem Mass Spectrometry (LC/MS/MS) analysis as described in Le Dû-Lacoste (2008).

\subsection{Biological analysis}

\subsubsection{Lethal and morphological analyses}

Lethal and sublethal morphological endpoints were recorded as described in Lammer et al. (2009). Briefly, mortality and hatching success were daily monitored during zebrafish exposures. Survival monitoring was prolonged until $15 \mathrm{dpf}$. After an exposure of 96 hours, biometric analysis (standard body and head lengths, whole body and yolk sac surfaces) and abnormalities were recorded following methods reported in Perrichon et al. (2014). Five categories of abnormalities were scored: 1- Edemas (brain, pericardial, yolk sac); 2- Skeletal deformities (scoliosis, lordosis, tail bud); 3- Craniofacial deformities (jaw, development of eyes, head); 4- Cardiac deformities (anemia, hemorrhage, atrium/ventricle size, blood circulation, heart position); 5- Yolk sac malabsorption. Moreover, a scoring matrix (score of 0-3) was applied 
following occurrence and severity of these abnormalities: (0) healthy larvae, (1) one abnormality or mild-affected larvae, (2) two abnormalities or moderately affected larvae, (3) three abnormalities or more abnormalities or severely affected larvae. Results were expressed as percentages of surviving larvae.

\subsubsection{Swimming ability}

PhotoMotor behavioral Response (PMR) on 120 hpf larvae were monitored, following the procedure described by Péan et al. (2013) with slight modifications (Perrichon et al. 2014). Briefly, swimming activity of larvae was recorded during a light/dark change challenge in a temperature-controlled box $\left(28 \pm 0.5^{\circ} \mathrm{C}\right)$. This challenge consists of three successive alternating light cycles of 5 min: light On (1), light Off and light On (2). Video analysis was performed with Ethovision XT 8.5 software (Noldus, The Netherlands). The behavioral activity was assessed by measuring the total swimming distance $(\mathrm{cm})$ during all this light/dark challenge. This distance is calculated considering the center point of the larvae between two consecutive $\mathrm{X}-\mathrm{Y}$ coordinates summed over a 5-min cycles.

\subsubsection{Cardiac activity}

Cardiac activity was recorded at $28 \pm 1{ }^{\circ} \mathrm{C}$ on $120 \mathrm{hpf}$ larvae. Larvae were introduced in 1 $\mathrm{mm}$ wide lines molded in agarose (2\%), immobilized with $3 \%$ methylcellulose (diluted in artificial water) and positioned in a lateral view. An acclimation of 2 hours in the system was then performed before analysis in order to stabilize heartbeat. Heartbeats were recorded under dissecting microscope (Olympus SZX9, 40x) coupled to a camera (DMK 31AU03, The Imaging Sources, Germany) at 15 frames per second and IC Capture 2.2 software (The Imaging Sources, Germany). Larvae were placed under dissecting microscope two minutes before recording their heartbeats in order to acclimatize them to the light microscope. For each larva, three successive movies of $30 \mathrm{~s}$ were acquired. Video analysis was then performed with the Heartbeat detector function of Ethovision XT 9.0 software (Noldus, The Netherlands), which is designed for analyzing frequencies of both cardiac chambers contractions (atrium and ventricle). Heart activity was expressed in beat per minutes. 


\subsubsection{In vivo EROD activity}

EROD activity as indicator of phase I biotransformation activity was determined individually following procedure described by Perrichon et al. (2014). To summarize, these activity measurements were performed on $96 \mathrm{hpf}$ surviving larvae. Zebrafish larvae were incubated in 7-ethoxyresorufin solution (CYP1A substrate, $21 \mu \mathrm{g} . \mathrm{L}^{-1}$ ) for 5 hours at $28 \pm 0.5^{\circ} \mathrm{C}$. Levels of produced resorufin into gastrointestinal cavity were observed by fluorescence microscopy (Rhodamin red filter, excitation/emission, 560/580 nm). The emitted-fluorescence was quantified using imaging analysis software ImageJ (Schneider et al. 2012) coupled with HeatMap Histogram plugin (Péan S., http:/www.samuelpean.com/heatmap-histogram/). Fluorescence results were expressed in integrated density of pixels (arbitrary unit).

\subsubsection{DNA integrity}

DNA strand break measurements by the alkaline comet assay were performed on $24 \mathrm{hpf}$ embryos. Pools of five dechorionated embryos per replicate were digested with $1 \mathrm{mg} . \mathrm{mL}^{-1}$ of phosphate-buffered saline 1X/collagenase IV from Clostridium histolyticum (PBS 1 X, 137 mM $\mathrm{NaCl} \cdot \mathrm{KCl} 2.7 \mathrm{mM} \cdot \mathrm{Na}_{2} \mathrm{HPO}_{4} 10 \mathrm{mM} \cdot \mathrm{KH}_{2} \mathrm{PO}_{4} 1.8 \mathrm{mM}$, pH 7.4, Sigma-Aldrich, Germany) during 45 minutes at room temperature. Cell suspension was filtered through a $48 \mu \mathrm{m}$ gauze in order to separate individual cells from tissue debris. Following a centrifugation for 10 minutes at $2300 \mathrm{rpm}$ at room temperature, cells pellet was resuspended in $30 \mu \mathrm{l}$ of PBS. Then, the comet assay was performed as described by Akcha et al. (2003). For each cell sample, two slides were prepared. DNA was stained with $70 \mu \mathrm{L}$ of GelRed ${ }^{\mathrm{TM}}$ solution $(1 / 10000)$ for one hour at $4{ }^{\circ} \mathrm{C}$ in the dark. Slides were analyzed using a fluorescence microscope (Olympus BX60, 400x) coupled to a Luca-S EMCCD camera (Andor ${ }^{\mathrm{TM}}$ technology, Northern Ireland) and imaging analysis software (Komet 6.0, Andor ${ }^{\mathrm{TM}}$ Technology, Northern Ireland). Genotoxicity was assessed by measuring the DNA percentage in the comet tail for at least 50 nuclei per slide.

\subsubsection{Gene transcription}


PCR primers were designed with Primer3 software (Rozen and Skaletsky, http://bioinfo.ut.ee/primer3-0.4.0/). The accession numbers of the 8 selected genes (cytochrome P4501A, aryl hydrocarbon receptor 2, catalase, Cu/Zn-superoxide dismutase, Mn-superoxide dismutase, glutathione peroxidase 4, bcl-2-binding component 3, bcl-2-associates X protein) and the corresponding primers are reported in Table 2.

Larvae were sampled at the end of exposure (96 hpf) and stored in RNA later (SigmaAldrich) at $-20^{\circ} \mathrm{C}$ until used. Total RNAs were extracted on 20 pooled larvae using Trizol ${ }^{\circledR}$ Reagent (Invitrogen, Carlsbad, CA, USA) following the manufacturer's instructions with chloroform/ethanol purifications. Total RNA concentration was quantified by spectrophotometry at $260 \mathrm{~nm}$. Furthermore, purity of RNAs was verified by measuring the A260/A230 nm and A260/A280 nm ratios and by electrophoresis on a 1.8\% agarose gel with ethidium bromide staining. To avoid genomic DNA contamination, RNA samples were digested by RNase-free DNase I (Promega Madison, USA) and then purified.

First-strand cDNA was synthetized from $1 \mu \mathrm{g}$ total RNAs. Reaction mix included $500 \mathrm{ng}$ of oligo $\left(\mathrm{d}_{\mathrm{T}}\right)_{15}, 250 \mathrm{ng}$ of random hexamer primers (Promega, Madison, USA), and $10 \mathrm{mM}$ of deoxyribonucleotide triphosphate (dNTPs) for a final volume of $10 \mu$. The reaction was initiated using $2.5 \mu \mathrm{L}$ of M-MLV Reverse Transcriptase 5X (Promega, Madison, USA) following manufacturer's instructions. Reverse transcription reaction was carried out for $1 \mathrm{~h}$ at $42{ }^{\circ} \mathrm{C}$ in an Eppendorf Mastercycler and inactivated by heating for $15 \mathrm{~min}$ at $70^{\circ} \mathrm{C}$. The cDNA mixture was stored at $-20^{\circ} \mathrm{C}$ until real-time PCR analysis.

Real-time PCR reactions were performed in sterile 96-wells PCR microplates with StepOnePlus $^{\mathrm{TM}}$ instrument (Applied Biosystems ${ }^{\circledR}$, Life Technologies USA) following the manufacturer's instructions. Quantification procedure was based on fluorescence of the reaction mixture which is related to the total amount of labeled double-stranded DNA. The reaction mixture contained $10 \mu \mathrm{L}$ of Fast SYBR ${ }^{\circledR}$ Green Master Mix 5 X (Applied Biosystems ${ }^{\circledR}, \mathrm{USA}$ ), $2.4 \mu \mathrm{L}$ of primers at $600 \mathrm{nM}$ (Eurofins MWG Operon, Germany), 5.6 $\mu \mathrm{L}$ of Milli-Q water and 2 $\mu \mathrm{L}$ of cDNA. Thermal cycling conditions were: enzymatic activation during $10 \mathrm{~min}$ at $95^{\circ} \mathrm{C}$, followed by 40 cycles including a denaturation step $\left(95^{\circ} \mathrm{C}, 15 \mathrm{~s}\right)$, a hybridization step $\left(60^{\circ} \mathrm{C}, 40\right.$ s) and an annealing step $\left(72^{\circ} \mathrm{C}, 30 \mathrm{~s}\right)$.

The specificity of the process has been verified after completion of the PCR run, by testing the nature of the amplified product with gel electrophoresis and melting curves. 
Gene expression levels were quantified from the threshold cycle (CT) number and normalized with four housekeeping genes (glyceraldehyde-3-phosphate dehydrogenase, eukaryotic elongation factor 1, glucose-6-phosphate dehydrogenase, beta-actin).

\subsection{Statistical analysis}

The number of individuals sampled for chemical and biological analyses was reported in Table 3. Statistical analyses were performed using Statistica 9.0 software (StatSoft, USA) with significant level of 5\%. Comet assay data were normalized using a logarithm transformation (Zar 2010). Biological endpoints of fish exposed to the different concentrations of WAF were analyzed with nested-ANOVA (N-ANOVA), followed by a post hoc Tukey test. When the parametric assumption of normality (Shapiro-Wilk tests) and homoscedasticity of variance (Levene tests) were not respected, the non-parametric Kruskal-Wallis (KW) test and multiple pairwise comparisons were conducted. Behavioral data were analyzed using a one-way repeated measure ANOVA (R-ANOVA) with exposure concentrations as a dependent factor and light as a fixed factor. A post hoc Newman Keuls test was performed when a significant difference was detected. These results were expressed as mean \pm standard error of mean (SEM). The survival, hatching and abnormalities data, expressed in percentage, were analyzed with Chi-square tests to detect significant differences between exposure conditions. Gene expressions were analyzed with a Relative Expression Software Tool REST-2009C (Qiagen, http://www.REST.de.com). The gene expression level was given in relative expression ratio compared to the control condition.

\section{Results}

\subsection{Chemical analysis}

During the experiment period, the WAF concentration renewal was stable for the tested concentrations (results not shown). In the control group, the background water level of PAHs was low (Table 1 and 4). 
The concentrations of PAHs linearly decreased with WAF dilutions (Table 4). The total PAH concentration ranged from $6158.5 \pm 3705.4$ ng. $\mathrm{L}^{-1}$ to $170808.9 \pm 4479.9 \mathrm{ng} . \mathrm{L}^{-1}$ in WAF prepared with Arabian light oil and from $26105.4 \pm 3527.6$ ng.L $\mathrm{L}^{-1}$ to $257028.5 \pm 47230.7$ ng.L ${ }^{-1}$ in WAF prepared with Erika fuel oil. Regarding the 16 PAHs listed priority by US-EPA, the portion of LMW PAHs (from $197.3 \pm 75.0$ to $6040.6 \pm 249.3 \mathrm{ng} . \mathrm{L}^{-1}$ ) were predominant compared to HMW PAHs (from $4.3 \pm 0.1$ to $17.8 \pm 1.1$ ng. $\mathrm{L}^{-1}$ ) in BAL WAF (Table 4). Furthermore, the BAL WAF were characterized by a greater amount of aromatic sulphurated compounds (sulpPAHs and MDBT) compared to HFO WAF. Regarding the sum of TPAHs, the concentration of BAL_10\% WAF appeared to be of same order of magnitude to that of the HFO_10\% WAF. However, the portion of the 16 priority PAHs, was 1.6 -fold higher in HFO_10\% WAF than in BAL_10\% WAF, which makes it difficult the direct comparison of these both dissolved fractions of oil, in terms of composition. A higher proportion of phenanthrene (parent and methylated molecules) seems to be identified in HFO WAF. Even if the HMW PAHs such as pyrene, fluoranthene, benzo[a]pyrene do not appear in significant concentrations, their presence, as well as that of methylchrysene (from $34.3 \pm 7.4$ to $114.9 \pm 36.4$ ng.L ${ }^{-1}$ ), a compound undetected in BAL WAF, characterize the dissolved fractions of Erika oil.

\subsection{Survival and hatching success}

Survival and hatching rates measured following WAF exposures are shown in Figure 2. In the both Control groups, survival rates were $95.3 \pm 1.7 \%$ after exposure to BAL (Fig. 2A) and HFO (Fig. 2B) WAFs (96 hpf). After 264 hpf, a basal mortality of unfed larvae was observed in both of control groups with a survival rate that decreased to $4.3 \pm 3.3 \%$ and $7.3 \pm 2.6 \%$ for BAL and HFO WAFs, respectively, at the experiments' end (360 hpf). Whatever the tested WAF 
concentration, BAL and HFO WAFs did not induce any significantly lethal effects on zebrafish embryos and larvae during the exposure period (from 1.5 to $96 \mathrm{hpf}$ ). The survival rates ranged from $93.3 \pm 1.6 \%$ to $96.0 \pm 1.2 \%$ for BAL WAF exposures (Fig. 2A) (Chi-square, $\mathrm{p}=0.74$ ) and from $89.3 \pm 2.2 \%$ to $93.3 \pm 1.7 \%$ for HFO WAF exposures (Fig. 2B) (Chi-square, $p=0.25$ ). During the observation period (from $96 \mathrm{hpf}$ ) in control water, no significant mortality was brought about with any BAL WAF concentrations when compared to the Control group (Chisquare, $\mathrm{p}>0.05)$. The basal mortality of larvae contaminated by BAL WAF followed the same kinetics as the Control group whatever the exposure concentration was (Fig. 2A). Following HFO WAF exposure (Fig. 2B), the highest concentration HFO_100\% WAF caused a significant decrease in survival rate compared to other exposure concentrations, from $144 \mathrm{hpf}$ until the experiments' end (Chi-square, $\mathrm{p}<0.001)$.

Regarding hatching success, $7.6 \pm 2.2 \%$ and $4.2 \pm 1.9 \%$ at $48 \mathrm{hpf}$ and $84.7 \pm 4.9 \%$ and $86.1 \pm 4.5 \%$ of the Control zebrafish embryos hatched out of the chorion between 48 and $72 \mathrm{hpf}$. Hatching success reached around $100 \%$ at $96 \mathrm{hpf}(99.3 \pm 0.5 \%$ and $100 \pm 0.0 \%$ for BAL and HFO WAFs, respectively) (Fig. 2C and 2D). No significant reductions in hatching rates were recorded in larvae exposed to BAL WAF versus the Control larvae at the end of exposure (Fig. 2C). Similar results were observed after HFO_10\% WAF and $\mathrm{HFO} 50 \%$ WAF exposures with around $100 \%$ of hatched larvae at the end of exposure (Fig. 2D). However, the highest concentration of HFO WAF (HFO_100\% WAF) induced a significant hatching delay with $60.0 \pm$ $11.4 \%$ at $72 \mathrm{hpf}$ and $83.5 \pm 5.5 \%$ at $96 \mathrm{hpf}$ (Chi-square, $\mathrm{p}<0.001)$.

\subsection{Developmental defects}


Biometric measurements of $96 \mathrm{hpf}$ larvae exposed to BAL and HFO WAFs are shown in Table 5. At the end of the exposure period, the standard lengths in Control larvae were $3.67 \pm$ $0.04 \mathrm{~mm}$ and $3.77 \pm 0.02 \mathrm{~mm}$ for BAL and HFO WAFs experiments, respectively. Larvae exposed to BAL_1\% $(3.79 \pm 0.02 \mathrm{~mm})$ and $B A L \_10 \%(3.78 \pm 0.03 \mathrm{~mm})$ WAF were significantly larger in size than the Control larvae (N-ANOVA, $\mathrm{p}=0.01$ and $\mathrm{p}=0.03$, respectively). BAL WAF did not evoke any significant modifications in other biometric parameters (head/body length ratio, yolk sac surface and yolk sac/whole larval surface ratio) in zebrafish larvae. Regarding HFO WAF exposure, larvae exposed to HFO_100\% WAF were $0.2 \mathrm{~mm}$ smaller than the Control group (N-ANOVA, $\mathrm{p}<0.001$ ). No significant differences, compared to the Control larvae, were seen in the head/body length ratio, yolk sac length and yolk sac/whole larvae surface ratio in larvae exposed to the different concentrations of HFO WAF (N-ANOVA, $\mathrm{p}>0.05$ ).

The percentage of abnormal individuals observed at $96 \mathrm{hpf}$ as well as the various abnormalities and their severity are also summarized in Table 5. BAL WAF exposures did not induce significant increase of morphological abnormalities versus the Control group (Chi-square, $\mathrm{p}=0.39$ ) whereas the HFO WAF induced a concentration-dependent increase of abnormalities, accounting for 2.7, 1.8, 22.0 and $91.1 \%$ of abnormal individuals for the Control, HFO_10\%, HFO_50\% and HFO_100\% groups, respectively (Chi-square, $\mathrm{p}<0.001)$. Regarding the occurrence of abnormalities, $18.0 \%$ of abnormal larvae exposed to HFO_ $50 \%$ presented at least one kind of deformation (score 1). A major proportion of these abnormalities were comprised of edemas (13.9\%). Larvae exposed to HFO_100 \% WAF were for $28.9 \%$ mildly affected (score 1), $20.0 \%$ moderately affected (score 2), $42.2 \%$ severely affected (score 3 or more) in terms of abnormalities. Among these deformations, it was observed that $41.6 \%$ were edemas $(100 \%$ of pericardial edemas, $41.5 \%$ yolk sac edemas, results not shown), $19.4 \%$ were cardiovascular failures and $16.5 \%$ were craniofacial defects. 
3.4. Swimming and cardiac activities

Figure 3 portrays the PMR of zebrafish larvae (at $120 \mathrm{hpf}$ ) following exposure to both BAL and HFO WAFs. Response patterns of Control larvae were similar during the three activity phases (Light On (1), Light Off and Light On (2)) of the challenge for the BAL and HFO WAF experiments. An increasing swimming activity was observed during the sudden darkness period (R-ANOVA, $\mathrm{p}<0.001)$. Then, a recovery phase was observed, in which the second Light On period exhibited a similar (BAL WAF) or close (HFO WAF) response pattern to the first Light Onperiod. Regarding the BAL WAF exposure (Fig. 3A), the response patterns were similar to the Control group and no significant modifications in locomotor activity were found with the different concentrations (R-ANOVA, $\mathrm{p}>0.05$ ). Larvae exposed to the highest concentration of HFO WAF (HFO_100\%) swam a significantly reduced distance than the Control and larvae exposed to $\mathrm{HFO}_{-} 10 \%$ and $50 \%$. (from 7.9- to 8.6-fold lower in the Light On (1) and from 3.0 to 3.2-fold in the Light On (2) phases, ANOVA, p<0.001) (Fig. 3B). During the stress phase (Light Off), the distance moved by the larvae were not significantly different than the others conditions (ANOVA, $\mathrm{p}>0.05$ ).

With respect to cardiac activity, no significant differences were observed in heartbeat of $120 \mathrm{hpf}$ larvae exposed to the various concentrations of BAL WAF (Fig. 4). On the contrary, a significant drop in heartbeats was measured in larvae exposed to HFO_100\% WAF (KW, $\mathrm{p}<0.05)$.

\subsection{EROD activity}


EROD activity in larvae exposed to both WAFs is described in Fig. 5. A significant increase in EROD activity compared to the Control (2.6-fold) was observed in larvae exposed to BAL WAF but only at the highest tested concentration (N-ANOVA, $\mathrm{p}<0.001$ ). A 3.4-fold increase in activity was also observed by raising the BAL WAF concentration from 10 to $100 \%$. The HFO WAF exposure led to a concentration-dependent increase of EROD activity in zebrafish larvae, with inductions 4.1-, 5.5- and 7.8-fold higher than the Control group for HFO_10\%, HFO_50\% and HFO_100\% WAF concentrations, respectively $(\mathrm{KW}, \mathrm{p}<0.001)$.

\subsection{DNA integrity}

At $24 \mathrm{hpf}$, the comet parameter, tail DNA, measured in the Control and WAF-exposed larvae was less than 10\%. For both BAL and HFO WAF-exposed larvae, the levels of DNA strand breaks were not significantly different from that of Control larvae (Fig. 6A and 6B), except for BAL_100\% WAF where the cell counts were significantly lower (N-ANOVA, $\mathrm{p}=0.001$ ). These results point to the absence of genotoxic effects from WAF exposure.

\subsection{Gene transcription}

The relative expressions of target genes compared to their respective Controls are presented in Table 6. Data obtained for BAL and HFO WAFs were normalized using four housekeeping genes, eukaryotic elongation factor 1 (eef1), beta-actin (Bactin), glucose-6phosphate dehydrogenase $(g 6 p d)$ and glyceraldehyde-3-phosphate dehydrogenase (gapdh).

The gene encoding for cytochrome P4501A (cypla) was 1.27- and 3.99-fold upregulated for the two highest BAL WAF concentrations ( $\mathrm{p}=0.004$ and 0.002 , respectively). Cypla was 
upregulated from 2.04- to 8.31-fold for the three tested concentrations of HFO WAF ( $\mathrm{p}=0.004$; 0.002 and 0.002, respectively). Concerning the transcription level of aryl hydrocarbon receptor 2 $(a h r 2)$, it was only significantly increased following exposure to the lowest HFO WAF concentration $(\mathrm{p}=0.03)$.

Regarding antioxidant defenses, genes encoding for glutathione peroxidase 4 (gpx4), Cu/Zn-superoxide dismutase ( $\operatorname{sod}(\mathrm{Cu} / \mathrm{Zn})$ and $\mathrm{Mn}$-superoxide dismutase $(\operatorname{sod}(\mathrm{Mn}))$ were slightly upregulated in larvae exposed to BAL WAF. Gpx4 expression was also slightly increased in BAL_10\% and BAL_100\% WAF. Sod $(\mathrm{Cu} / \mathrm{Zn})$ expression was 1.12- to 1.24-fold higher than in the Control group $(\mathrm{p}<0.05)$. An increase in the expression level of the antioxidant enzyme $\operatorname{Sod}(\mathrm{Mn})$ was only revealed at BAL_100\% WAF concentration $(\mathrm{p}=0.02)$. No significant change in catalase (cat) mRNA levels was observed in larvae exposed to BAL WAF.

For HFO WAF exposures, gpx4 expression was significantly upregulated at the highest concentration $(\mathrm{p}=0.03)$. In contrast to BAL WAF exposure, a significant increase of $c a t$-mRNA levels was found in larvae exposed to HFO WAF. Transcription levels were 1.25- to 1.42-fold above the Control group. $\operatorname{Sod}(\mathrm{Cu} / \mathrm{Zn})$ was also significantly upregulated for the two highest concentrations ( $\mathrm{p}=0.046$ and 0.02 , respectively). $\operatorname{Sod}(M n) m R N A$ was 1.39 -fold higher at the highest concentration versus the control group $(\mathrm{p}=0.01)$.

The apoptosis pathways (bcl-2-binding component 3, p53 and bcl-2-associates X protein bax) were not impacted by either HFO and BAL WAFs, except for the $p 53$ gene which was upregulated at the BAL_100\% WAF concentration $(\mathrm{p}=0.003)$.

3.8. PAH metabolites 
Quantification of hydroxylated PAH metabolites (OHPAHs) is shown in Fig. 7. In the Control group, the total sum of OHPAHs was $59.1 \pm 31.9 \mathrm{ng} \cdot \mathrm{g}^{-1}$ larvae for BAL WAF and $73.3 \pm$ 27.3 ng.g ${ }^{-1}$ larvae for HFO WAF. 3-OH-Fluo was not detected in larvae exposed to either WAF. The detected metabolites were not significantly different after exposure to BAL WAF (KW,

$\mathrm{p}>0.05$ ) (Fig. 7A). The 1-OH-Chrys and $\Sigma \mathrm{OH}-\mathrm{BaP}$ were only detected in larvae exposed to $\mathrm{HFO}$ WAF (Fig. 7B). The HFO WAF initiated a concentration-dependent increase of 1-OHPyr and 1OHChrys. The $\Sigma \mathrm{OH}-\mathrm{BaP}$ were present in the larvae exposed to the various concentrations of HFO WAF, significantly rising with HFO_100\% WAF.

\section{Discussion}

The aim of this study was to assess the toxicity of WAF from two different oil compositions: i) a brut Arabian light oil and ii) a heavy fuel oil from Erika, through an experimental system using a zebrafish embryo-larval assay.

\subsection{Chemical assessment of water-accommodated fractions}

In the context of hazard risk assessment, the use of dissolved fractions or WAF appeared suitable to evaluate the toxicity of petroleum compounds released into the environment through an oil spill (Martinez-Gomez et al. 2010). In our study, PAH concentrations in WAF decreased significantly (50-fold in mean) over the $24 \mathrm{~h}$ incubation at $28^{\circ} \mathrm{C}$ (results not shown). For this reason, the tested solution was renewed every day during the experiments using the same WAF stock solution. When stored at $4{ }^{\circ} \mathrm{C}$ in dark, this solution remained stable within the $96 \mathrm{~h}$ exposure period, validating the experimental protocol. Such a decrease in PAH concentrations in 
WAF solutions has already been observed by Couillard et al. (2005), suggesting a possible degradation, volatilization and/or uptake of compounds by fish larvae. In the present study, the high temperature of incubation likely increased the loss of the dissolved fraction.

The concentrations used in the present study were chosen to cover a wide range of PAH concentrations found in the environment after oil spills. Indeed the concentrations for BAL WAF

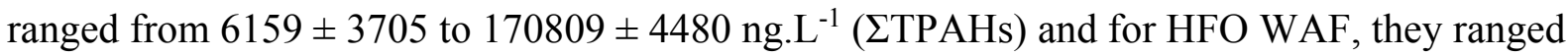
from $26105 \pm 3528$ to $257029 \pm 47231 \mathrm{ng} . \mathrm{L}^{-1}$ (Table 4). Law (1978) recorded concentrations from 2200 up to $200000 \mathrm{ng} \cdot \mathrm{L}^{-1}$ in water sampled at a depth of $1 \mathrm{~m}$ after the Amoco Cadiz oil spill. This author also reported a concentration of aromatic hydrocarbons up to $1700 \mathrm{ng} . \mathrm{L}^{-1}$ after the Ekofisk Bravo blowout in 1977 (Law 1978b). After the Prestige oil spill in 2002, PAH concentrations in seawater reached 28800 ng.L.-1 (Bado-Nilles et al. 2009b; González et al. 2006). The concentrations documented following the Exxon Valdez and Erika spills were, respectively, $600000 \mathrm{ng} . \mathrm{L}^{-1}$ and from 23.5 to $54.9 \mathrm{ng} . \mathrm{L}^{-1}$ in coastal waters (Boehm et al., 2007; Tronczynski et al., 2004).

The composition of the prepared dissolved fractions are consistent with the specific PAH profile of brut Arabian light and Erika heavy fuel oils described in the literature (Geffard et al. 2004; Saeed and Al-Mutairi 2000; Tronczynski et al. 2004). Certainly, Erika fuel oil consists mainly of alkylated compounds of naphtalene, phenanthrene, pyrene and chrysene and HMW PAHs when compared to BAL oil. Conversely, BAL oil is characterized by a higher concentration of sulphurated PAHs and their homolog compounds with a large proportion of LMW PAHs.

4.2. Survival/hatching and developmental defects 
BAL WAFs did not display any lethal effect or developmental disruption in zebrafish embryo-larval development with whatever the tested concentration was (Fig. 2A, 2C and Table 5). On the contrary, WAF from Erika oil spills (HFO) was acutely toxic for larvae exposed at the highest concentration (Fig. 2B and 2D). This indicates that direct embryonic exposure may have important consequences on larval survival and may impact the fish recruitment under environmental conditions. This lethal body burden might be explained by the high incidence and severity of different morphological abnormalities observed in the larvae exposed to high concentration of HFO WAF (Table 5). Indeed, $40.0 \%$ to $91.1 \%$ of abnormal larvae were severely affected by edemas (41.6\%) as well as cardiovascular (19.4\%) and craniofacial (16.5\%) disruptions. These deleterious effects were deemed more severe as the larvae were significantly smaller. Despite the body burden in larvae exposed to lowest concentrations of HFO WAF, no acute effect was recorded.

Our toxicological data are consistent with previous studies reporting acute and/or developmental effects of PAH mixtures on fish ELS (Carls and Thedinga, 2010; Cachot et al., 2007; Hose et al., 1996; Kammann et al., 2004; Kocan et al., 1996; Marty et al., 1997; Tilseth et al., 1984). However, a direct comparison is difficult due to differences in oil composition (mixture or oil) and concentrations plus exposure time between studies. Furthermore, it was shown in literature that the toxicity threshold for marine species are lower than they are for zebrafish, from 10 to 100 times lower (Incardona et al. 2014).

Lethal and sublethal effects observed in the present study might be associated with a reduction in the use of nutritional reserves, and therefore of the energy required for optimal physiological mechanism functioning (Billiard et al. 1999; Carls and Thedinga 2010). This is one of the reasons why survival monitoring should be prolonged after the exposure period in order to assess the ability of starved larvae to draw upon their reserves and to survive (Örn et al. 1998). 


\subsection{Behavioral toxicity assessment}

Based on motor responses (perception and reaction) to stimuli closely associated to swimming activity, the PMR of larval zebrafish were analyzed in order to evaluate the developmental neurotoxicity of spilled petroleum-related compounds (Fig. 3). Whichever the fraction considered, PMR patterns during the challenge were consistent with those found in the literature, dissociating three swimming activity phases: i) basal swimming activity phase (Light On(1)), ii) challenge phase or stress phase (Light Off) causing an increase in swimming activity and iii) the recovery phase during which swimming activity returns to the basal level in the new light phase (Kokel et al. 2010; MacPhail et al. 2009; Padilla et al. 2011).

The BAL WAF did not induce any swimming activity change in response to the light stress (Fig. 3A). However, an interesting response was demonstrated by larvae exposed to the highest concentration of HFO WAF (Fig. 3B). Indeed, compared to their basal swimming activity level, HFO_100\%-exposed larvae swam, on average, 8.3-fold less distance-wise than other exposed groups (HFO_10\%, HFO_50\%) or unexposed larvae. Despite an important interindividual variability, the larvae exposed to $\mathrm{HFO}_{-} 100 \%$ reacted to a second stress (Light Off) in a similar manner than other exposed- and Control larvae in terms of distance moved and swimming speed (results not shown). As well, the larvae exposed to HFO_100\%returned to basal swimming activity levels when the light was switched back on. This notable reduction in swimming activity was closely linked with morphological impairments. Indeed, mildly to severely affected larvae engaged in a minimum of vital swimming for their survival, but in the case of sudden stress (e.g. predation), they would be unable to rapidly react. And, as previously observed, their survival was more limited than control larvae. 
Information on fish PMR following exposure to pollutants is limited to only a few studies (Péan et al. 2013; Usenko et al. 2011) and to the best of our knowledge, no data about the impact of PAH mixtures is currently available in the literature, limiting comparisons. In zebrafish (Danio rerio) and Japanese medaka (Oryzias latipes) exposed to PAH-contaminated sediments, modulations in PMR were recorded dependent on the exposed compound. Fluoranthene $\left(10 \mu \mathrm{g} . \mathrm{g}^{-}\right.$ 1, 3-benzenic rings PAH) led to a reduction of distance moved by larval zebrafish whereas benzo[a]pyrene $\left(10 \mu \mathrm{g} \cdot \mathrm{g}^{-1}\right.$, 5-benzenic rings $\left.\mathrm{PAH}\right)$ increased swimming activity in Japanese medaka (Perrichon et al. 2014). Through the PMR analysis, both BAL and HFO WAFs did not elicit behavioral abnormalities in the larvae exposed whatever the tested concentration. We also note that these behavioral analyses did not assess the swimming performance (strict sense) of larvae but aimed to test their ability to rapidly react to a second stress, which could be a benefit when escaping a predator or a polluted area, or to capture prey. The behavioral consequences observed might be directly associated to the morphological alterations or representative of physiological impairments. The body burden observed in larvae exposed to oil might trigger a strong energy demand. Consequently, larvae might reduce their swimming activity to gain energy and allocate it for vital functions (cardiac, respiratory) to maintain a good fitness.

\subsection{Cardiotoxicity assessment}

Once more, the BAL fraction did not induce any cardiac disruptions at any of the tested concentrations (Fig. 4). However, the lethal and sublethal effects previously observed in larvae exposed to HFO_50\% and HFO_100\% WAFs could be the direct consequences of metabolism impairments induced by petroleum compound exposure (Billiard et al. 1999; Rhodes et al. 2005). Indeed, we observed defects in heartbeat in $120 \mathrm{hpf}$ larvae exposed to the highest concentration 
of HFO WAF (Fig. 4). The observed bradycardia is consistent with the direct influence that was observed on cardiac morphogenesis. Among the abnormal larvae recorded in the present study, a major percentage of the malformations were of a pericardial and cardiovascular nature (e.g. anemia, hemorrhages, peripheral vascular defects, respective position of atrium and ventricle). However, no heartbeat difference was recorded with larvae exposed to HFO_50\% WAF, though $22.0 \%$ of larvae were deformed.

Disruption in cardiac functioning will be primarily affected by oil exposure and may lead to important consequences for survival during later developmental stages and consequently could be deleterious for fish recruitment. Recent studies have documented the cardiotoxic action of PAHs in fish ELS, with bradycardia, irregular arrhythmia and morphogenesis disturbances (González-Doncel et al., 2008; Hicken et al., 2011; Incardona et al., 2011, 2010, 2009, 2006, 2005, 2004; Scott et al., 2011). Heartbeat was also decreased in Pacific herring (Clupea pallasi) and zebrafish (Danio rerio) embryos following a water soluble fraction (WSF) exposure of Alaska crude oil $\mathrm{n}^{\circ} 2\left(\Sigma \mathrm{TPAH}=9.3 \mu \mathrm{g} \cdot \mathrm{mL}^{-1}\right.$; Middaugh et al., 1998, 1996) and after sediment eluates/extracts exposure (Strmac et al. 2002). In 2010, Claireaux and Davoodi described a reduction of cardiac output (heart rate and stroke volume) in oil-exposed common sole (Solea solea). The ventricular contractility of developing zebrafish has been seen reduced after exposure to high energy WAF of Iranian and Alaska crude oils (Jung et al. 2013). Recently, Brette et al. (2014) have established that the physiological mechanism underlying to these cardiotoxic action previously observed, might be due to a blockade of the excitation-contraction coupling in cardiomyocytes. Further, the abundance of parent tricyclic PAHs and their alkylated homologs in weathered crude oil or PAH mixtures could be the etiology of cardiac dysfunction in fish embryos (Heintz et al. 1999; Incardona et al. 2005; 2004; Jung et al. 2013). 


\subsection{Genotoxicity assessment}

Surprisingly, no significant difference in DNA damage levels were observed following exposure to both WAFs in 24 hpf embryos(Fig. 6). As a matter of fact, it has been shown that some PAHs and their metabolites have the ability to interact with DNA that leads to a number of structural DNA lesions, such as chromosomal modifications, cross-linkages, strand breaks or DNA adducts (Kosmehl et al. 2008; Nogueira et al. 2009; Xue and Warshawsky 2005). In case of non-reparation, these DNA damages may affect development, growth dynamic, reproduction and therefore organism's fitness (Lawrence and Hemingway 2003; Xue and Warshawsky 2005). The early analysis (24 hpf) of these forms of damage may be an explanation for the lack of significant results. Recently, Le Dû-Lacoste et al. (2013) have demonstrated that genotoxic responses of turbot exposed to PAH mixtures ( $\left.2 \mathrm{TPAH}=6602-69285 \mathrm{ng} . \mathrm{L}^{-1}\right)$ extracted from Erika fuel oil was only significant after four days of exposure. A minimal time to onset toxic mechanisms (enzymatic activation and metabolic system) could be necessary to reveal a positive response in the comet assay (Le Dû-Lacoste et al. 2013; Kammann et al. 2004). Consequently, we cannot definitively comment on genotoxic effects in zebrafish exposed to both oil fractions (BAL, HFO).

\subsection{Detoxification and antioxidant defenses assessment}

The induction of cytochrome P450 and its catalytic activity involved in phase I detoxification has been used in environmental biomonitoring as a sensitive biomarker of PAH exposure (van der Oost et al. 2003). An increase of cypla mRNA levels was observed in larvae exposed to both BAL_10\% and BAL_100\% WAFs (Table 6). This gene upregulation was not sufficient to induce a significant upregulation of ethoxyresorufin- $O$-deethylase (EROD) activity 
in BAL_10\%-exposed larvae whereas EROD was significantly raised in BAL_100\%-exposed larvae $\left(\Sigma \mathrm{TPAH}=170809 \pm 4480\right.$ ng. $\left.\mathrm{L}^{-1}\right)($ Fig. 5). In the same way, EROD activity and cypla upregulation were rose linearly based on the concentration of HFO WAF. Our findings have revealed that even though few morphological, behavioral or physiological alterations were observed in BAL_10\%-100\% WAFs and HFO_10\%-50\% WAFs, defense mechanisms were activated to prevent potential damage from petroleum compounds. CYP1a induction have been shown to play a protective role rather to enhance the toxicity of petrogenic PAHs in fish early life stages (Hicken et al. 2011). However, in our work, even if the, CYP1A and EROD activity inductions were obviously higher at the highest concentration of HFO WAF, the PAHs toxicity have counteracted this protective barrier, inducing morphological, behavioral and physiological disruptions.

Furthermore, the increase of these detoxification systems could be linked with the production of reactive oxygen species (ROS) or reactive PAH metabolites (Basu et al. 2001; van der Oost et al. 2003). Indeed, when the production of ROS exceeds the limit of antioxidant defenses within an organism, ROS can interact adversely with cellular components (DNA, proteins, membrane lipids), causing oxidative stress and ultimately cell death (Di Giulio and Meyer 2008). In the present study, the transcription of genes involved in antioxidant defenses (gpx, cat, sod) was slightly increased with the WAF concentrations of brut Arabian light and Erika heavy fuel oils (Table 6). This suggests a slight induction of oxidative stress in WAFexposed larvae. This oxidative stress appears to also be related to the induction of enzymatic detoxification systems.

Activation of antioxidant defenses could also play a protective role against petroleum compounds by preventing adverse effects in exposed larvae. However, while a slight upregulation of antioxidant genes was shown, their activation does not seem to stabilize the 
prooxidant-antioxidant system in HFO_50\% and HFO_100\% that both led to morphological damage and the subsequent lethal effects. Several studies have examined changes in oxidative stress in response to PAH exposure in aquatic organisms but most were concerned protein activity and not mRNA expression responses, focused exclusively on the exposure to single PAH compounds (Ferreira et al. 2005; Oliveira et al. 2008; Sun et al. 2006).

The modulation of antioxidant defenses appears to be a sensitive but highly variable marker and species specific. For instance, phenanthrene (3-benzenic rings $\mathrm{PAH}$ ) induced oxidative stress in golden grey mullet (Liza aurata) and in goldfish (Carassius auratus) (Oliveira et al. 2008; Sun et al. 2006). The concentrations used in these studies were relatively high. An increase of catalase activity was also reported in the liver of the African catfish (Clarias gariepinus) exposed for $196 \mathrm{~h}$ to crude oil (Achuba and Osakwe 2004). In contrast, antioxidant enzyme activities were modulated in golden grey exposed to chemically dispersed oil (Milinkovitch et al. 2011a; Milinkovitch et al. 2011b). Kerambrun et al. (2012) have also described the lack of modulation of catalase activity in sea bass (Dicentrarchus labrax) exposed to acute concentrations of crude oil. Throughout the literature, these antioxidant defenses appear less sensitive to pollutant exposure versus detoxification and biotransformation processes and little evidence are shown that they are important modes of toxicity of petroleum compounds.

The activation of detoxification systems and the potential production of ROS could be because of the production of reactive PAH metabolites, generally more toxic than their parent PAHs. While the results were not statistically different between WAF exposures for most PAH metabolites, a high proportion of $\mathrm{OH}-\mathrm{Pyr}, \mathrm{OH}-\mathrm{Chrys}$ and $\mathrm{OH}-\mathrm{BaP}$ were found in larvae exposed to HFO (Fig. 7B). Even still, we cannot directly associate these metabolites to the adverse effects observed in the present study, though they are known to induce physiological (e.g. cardiac dysfunction) and morphological (e.g. development abnormalities) impairments (Incardona et al. 
$2009 ; 2005 ; 2004$ ). These metabolites (mainly OH-Pyr) are currently observed as the predominant compounds metabolized by fish after PAH exposure (Brinkmann et al. 2010; Le DûLacoste et al. 2013). Additionally, OH-BaP is known to be a genotoxic metabolite and could be the origin of cellular damage causing adverse effects on fish morphology (Le Dû-Lacoste et al. 2013). While OH-Chrys was also present in HFO larvae as well as its parent and alkylated homologues in water, these compounds are not known to alter embryonic development (Incardona et al. 2009; 2004) but are high Cypla-inducers (Barron et al. 2004).

Evidence of exposure has been demonstrated in this study, but the observed effects cannot be directly linked to specific compounds constituting the WAF. Several investigations have found that alkylated compounds play an important role in oil toxicity (Fallahtafti et al. 2012; Knecht et al. 2013; Turcotte et al. 2011). An important proportion of alkyl PAHs (e.g. MPhe) are present in WAFs from crude oils but the observed-influence will probably result from a combination of compounds that will generate toxicity through different dependent- or independent-aryl hydrocarbon receptor pathways ( $a h r 2$ was not induced in our study). The narcotic action of LMW PAHs (mainly by naphthalene) might play an important role in the observed developmental toxicity whereas the HMW PAHs (e.g. pyrene, benzo[a]pyrene and/or chrysene) may modulate certain enzymatic activities, such as MFO activity. Further alkyl-PAH toxicity should be further evaluated in order to elucidate their specific impact on fish ELS.

In the study presented here, a zebrafish embryo-larval bioassay was employed as a tool to provide a more comprehensive phenotypic map for assessing the effects of pollution on development. The dissolved fractions from HFO induced a high level of toxicity In zebrafish larvae. The use of zebrafish ELS as model of water risk assessment should be cautionly used because of the high resistance level of this fish compared to marine species. Our findings 
strengthen once more, that the petroleum compounds (PAHs) affect specifically the cardiac function and swimming activity of developing fish. Future research should focus on these both physiological and behavioral functions and to understand the underlying foundations of these detrimental effects. The use of a zebrafish assay could be the subject of further investigations to assess the impact of early oil exposure (mechanistic point of view) on later stages and the ability of fish to ensure future generations.

\section{Acknowledgements}

Financial support for $\mathrm{PhD}$ grant was received by $\mathrm{P}$. Perrichon from both the Conseil Général de Charente Maritime and the Institut Français de Recherche pour l'Exploitation de la Mer (Ifremer). This work was supported by the French National Research Agency (ANR) in the frame of the Investments for the future Programme, within the Cluster of Excellence COTE (ANR-10-LABX-45)" It was realized in the frame of the ConPhyPoP research project and CPER A2E. This project CPER is co-funded by the European Union through the European fund of regional development.

Authors acknowledge the CEDRE (Center of Documentation, Research and Experimentation on Accidental Water Pollution) for providing crude oils and R. Kanan for his recommendations on WAF preparation. Noldus (The Netherlands) is acknowledged for providing a free trial of the Heartbeat detector. D. Leguay is acknowledged for technical support of zebrafish behavioral assays and L. Joassard for her help in RT-PCR analyses.

\section{References}

Achuba FI, Osakwe SA. Petroleum - induced free radical toxicity in African catfish (Clarias gariepinus). Fish Physiol Biochem 2004;29:97-103.

Akcha F, Vincent Hubert F, Pfhol-Leszkowicz A. Potential value of the comet assay and DNA adduct measurement in dab (Limanda limanda) for assessment of in situ exposure to genotoxic compounds. Mutat Res 2003;534:21-32. 
Aurand D V, Coelho GM. Proceedings of the fourth meeting of the chemical response to oil spills: ecological effects research forum. Rep. No. 96-01, Ecosyst. Manag. Assoc. Purcellville, VA, p 50

Bado-Nilles A, Quentel C, Auffret M, Le Floch S, Gagnaire B, Renault T, Thomas-Guyon H. Immune effects of HFO on European sea bass, Dicentrarchus labrax, and Pacific oyster, Crassostrea gigas. Ecotoxicol Environ Saf 2009a;72:1446-1454.

Bado-Nilles A, Quentel C, Thomas-Guyon H, Le Floch S. Effects of two oils and 16 pure polycyclic aromatic hydrocarbons on plasmatic immune parameters in the European sea bass, Dicentrarchus labrax (Linné). Toxicol Vitr 2009b;23:235-241.

Barron MG, Carls MG, Heintz R, Rice SD. Evaluation of fish early life-stage toxicity models of chronic embryonic exposures to complex polycyclic aromatic hydrocarbon mixtures. Toxicol Sci 2004;78:60-67.

Basu N, Billiard S, Fragoso N, Omoike A, Tabash S, Brown S, Hodson P. Ethoxyresorufin-Odeethylase induction in trout exposed to mixtures of polycyclic aromatic hydrocarbons. Environ Toxicol Chem 2001;20:1244-1251.

Billiard SM, Querbach K, Hodson P V. Toxicity of retene to early life stages of two freshwater fish species. Environ Toxicology Chem 1999;18:2070-2077.

Black JA, Birge WJ, Westerman GA, Francis PC. Comparative aquatic toxicology of aromatic hydrocarbons. Fundam Appl Toxicol 1983;3:353-3588.

Brette F, Machado B, Cros C, Incardona JP, Scholz NL, Block BA. Crude oil impairs cardiac excitation-contraction coupling in fish. Science 2014;343:772-776.

Brinkmann M, Hudjetz S, Cofalla C, Roger S, Kammann U, Giesy JP, Hecker M, Wiseman S, Zhang X, Wölz J, Schüttrumpf H, Hollert H. A combined hydraulic and toxicological approach to assess re-suspended sediments during simulated flood events. Part I-multiple biomarkers in rainbow trout. J Soils Sediments 2010;10:1347-1361.

Cachot J, Law M, Pottier D, Peluhet L, Norris M, Budzinski H, Winn R. Characterization of toxic effects of sediment-associated organic pollutants using the lambda transgenic medaka. Environ Sci Technol 2007;41:7830-7836.

Carls MG, Thedinga JF. Exposure of pink salmon embryos to dissolved polynuclear aromatic hydrocarbons delays development, prolonging vulnerability to mechanical damage. Mar Environ Res 2010;69:318-325. 
Claireaux G, Davoodi F. Effect of exposure to petroleum hydrocarbons upon cardio-respiratory function in the common sole (Solea solea). Aquat Toxicol 2010;98:113-119.

Coelho GM, Aurand D V. Proceedings of the sixth meeting of the chemical response to oil spills: ecological effects research forum. Rep. No. 97-01, Ecosyst. Manag. Assoc. Purcellville, VA, p 69

Couillard CM, Lee K, Légaré B, King TL. Effect of dispersant on the composition of the wateraccommodated fraction of crude oil and its toxicity to larval marine fish. Environ Toxicol Chem 2005;24:1496-1504.

Le Dû-Lacoste M, Akcha F, Dévier M-H, Morin B, Burgeot T, Budzinski H. Comparative study of different exposure routes on the biotransformation and genotoxicity of PAHs in the flatfish species, Scophthalmus maximus. Environ Sci Pollut Res 2013;20:690-707.

Le Dû-Lacoste M. Etude des phénomènes de biotransformation des hydrocarbures aromatiques polycycliques (HAP) par les organismes aquatiques (poissons). Relation expositiongenotoxicité. Université Bordeaux 1, France. Thesis (in French). 2008; pp 398.

Fallahtafti S, Rantanen T, Brown RS, Snieckus V, Hodson P V. Toxicity of hydroxylated alkylphenanthrenes to the early life stages of Japanese medaka (Oryzias latipes). Aquat Toxicol 2012;106-107:56-64.

Ferreira M, Moradas-Ferreira P, Reis-Henriques M. Oxidative stress biomarkers in two resident species, mullet (Mugil cephalus) and flounder (Platichthys flesus), from a polluted site in River Douro Estuary, Portugal. Aquat Toxicol 2005;71:39-48.

Geffard O, Budzinski H, LeMenach K. Chemical and ecotoxicological characterization of the "Erika" petroleum: Bio-tests applied to petroleum water-accommodated fractions and natural contaminated samples. Aquat Living Resour 2004;17:289-296.

GESAMP. Estimates of oil entering the marine environment from sea-based activities. London. Reports and Studies 2007;75:pp 96.

GESAMP. Impact of oil and related chemicals on the marine environment. London. Reports and Studies 2003;50: pp 192

Di Giulio RT, Meyer JN. Reactive oxygen species and oxidative stress. Toxicol. fishes, Taylor and. Washington DC. 2008; pp 273-324

González JJ, Viñas L, Franco MA, Fumega J, Soriano JA, Grueiro G, Muniategui S, LópezMahía P, Prada D, Bayona JM, Alzaga R, Albaigés J. Spatial and temporal distribution of 
dissolved/dispersed aromatic hydrocarbons in seawater in the area affected by the Prestige oil spill. Mar Pollut Bull 2006;53:250-259.

González-Doncel M, González L, Fernández-Torija C, Navas JM, Tarazona JV. Toxic effects of an oil spill on fish early life stages may not be exclusively associated to PAHs: studies with Prestige oil and medaka (Oryzias latipes). Aquat Toxicol 2008;87:280-288.

Heintz RA, Rice SD, Wertheimer AC, Bradshaw RF, Thrower FP, Joyce JE, Short JW. Delayed effects on growth and marine survival of pink salmon Oncorhynchus gorbuscha after exposure to crude oil during embryonic development. Mar Ecol Prog Ser 2000;208:205216.

Heintz RA, Short JW, Rice SD. Sensitivity of fish embryos to weathered crude oil: Part II. Increased mortality of pink salmon (Oncorhynchus gorbuscha) embryos incubating dowstream from weathered Exxon Valdez crude oil. Environ Toxicol Chem 1999;18:494503.

Hicken CE, Linbo TL, Baldwin DH, Willis ML, Myers MS, Holland L, Larsen M, Stekoll MS, Rice SD, Collier TK, Scholz NL, Incardona JP. Sublethal exposure to crude oil during embryonic development alters cardiac morphology and reduces aerobic capacity in adult fish. Proc Natl Acad Sci U S A 2011;108:7086-7090.

Hose JE, Mcgurk MD, Marty GD, Hinton DE, Brown ED, Baker TT. Sublethal effects of the Exxon Valdez oil spill on herring embryos and larvae: morphological, cytogenetic, and histopathological assessments, 1989 - 1991. Can J Fish Aquat Sci 1996;53:2355-2365.

Incardona JP, Carls MG, Day HL, Sloan C a, Bolton JL, Collier TK, Scholz NL. Cardiac arrhythmia is the primary response of embryonic Pacific herring (Clupea pallasi) exposed to crude oil during weathering. Environ Sci Technol 2009;43:201-207.

Incardona JP, Carls MG, Teraoka H, Sloan C, Collier TK, Scholz NL. Aryl Hydrocarbon Receptor-Independent Toxicity of Weathered Crude Oil during Fish Development. Environ Health Perspect 2005;113:1755-1762.

Incardona JP, Collier TK, Scholz NL. Defects in cardiac function precede morphological abnormalities in fish embryos exposed to polycyclic aromatic hydrocarbons. Toxicol Appl Pharmacol 2004;196:191-205.

Incardona JP, Collier TK, Scholz NL. Oil spills and fish health: exposing the heart of the matter. J Expo Sci Environ Epidemiol 2010;21:3-4. 
Incardona JP, Day HL, Collier TK, Scholz NL. Developmental toxicity of 4-ring polycyclic aromatic hydrocarbons in zebrafish is differentially dependent on $\mathrm{AH}$ receptor isoforms and hepatic cytochrome P4501A metabolism. Toxicol Appl Pharmacol 2006;217:308-21.

Incardona JP, Gardner LD, Linbo TL, Brown TL, Esbaugh AJ, Mager EM, Stieglitz JD, French BL, Labenia JS, Laetz CA, Tagal M, Sloan CA, Elizur A, Benetti DD, Grosell M, Block BA, Scholz NL. Deepwater Horizon crude oil impacts the developing hearts of large predatory pelagic fish. Proc Natl Acad Sci 2014;111:E1510-E1518.

Incardona JP, Linbo TL, Scholz NL. Cardiac toxicity of 5-ring polycyclic aromatic hydrocarbons is differentially dependent on the aryl hydrocarbon receptor 2 isoform during zebrafish development. Toxicol Appl Pharmacol 2011;257:242-249.

Incardona JP, Swarts TL, Edmunds RC, Linbo TL, Aquilina-Beck A, Sloan CA, Gardner LD, Block BA, Scholz NL. Exxon Valdez to Deepwater Horizon: comparable toxicity of both crude oils to fish early life stages. Aquat Toxicol 2013;142-143:303-316.

Incardona JP, Vines CA, Anulacion BF, Baldwin DH, Day HL, French BL, Labenia JS, Linbo TL, Myers MS, Olson OP, Sloan CA, Sol S, Griffin FJ, Menard K, Morgan SG, West JE, Collier TK, Ylitalo GM, Cherr GN, Scholz NL. Unexpectedly high mortality in Pacific herring embryos exposed to the 2007 Cosco Busan oil spill in San Francisco Bay. Proc Natl Acad Sci U S A 2012;109:E51-58.

Jung J-H, Hicken CE, Boyd D, Anulacion BF, Carls MG, Shim WJ, Incardona JP. Geologically distinct crude oils cause a common cardiotoxicity syndrome in developing zebrafish. Chemosphere 2013;91:1146-1155.

Kammann U, Biselli S, Hühnerfuss H, Reineke N, Theobald N, Vobach M, Wosniok W. Genotoxic and teratogenic potential of marine sediment extracts investigated with comet assay and zebrafish test. Environ Pollut 2004;132:279-287.

Kanan R. Développements méthodologiques pour l'extraction et l'analyse des polluants organiques d'intérêt pour l'environnement marin: Application aux hydrocarbures aromatiques polycycliques. Université Bordeaux 1, France. Thesis (in French) 2012; pp 283.

Kerambrun E, Le Floch S, Sanchez W, Thomas Guyon H, Meziane T, Henry F, Amara R. Responses of juvenile sea bass, Dicentrarchus labrax, exposed to acute concentrations of 
crude oil, as assessed by molecular and physiological biomarkers. Chemosphere 2012;87:692-702.

Knecht AL, Goodale BC, Truong L, Simonich MT, Swanson AJ, Matzke MM, Anderson K a, Waters KM, Tanguay RL. Comparative developmental toxicity of environmentally relevant oxygenated PAHs. Toxicol Appl Pharmacol 2013;271:266-275.

Kocan RM, Hose JE, Brown ED, Baker TT. Pacific herring (Clupea pallasi) embryo sensitivity to Prudhoe Bay petroleum hydrocarbons: laboratory evaluation and in situ exposure at oiled and unoiled sites in Prince William Sound. Can J Fish Aquat Sci 1996;53:23662375 .

Kokel D, Bryan J, Laggner C, White R, Cheung CYJ, Mateus R, Healey D, Kim S, Werdich AA, Haggarty SJ, Macrae CA, Shoichet B, Peterson RT. Rapid behavior-based identification of neuroactive small molecules in the zebrafish. Nat Chem Biol 2010;6:231-237.

Kosmehl T, Hallare A V, Braunbeck T, Hollert H. DNA damage induced by genotoxicants in zebrafish (Danio rerio) embryos after contact exposure to freeze-dried sediment and sediment extracts from Laguna Lake (The Philippines) as measured by the comet assay. Mutat Res 2008;650:1-14.

Lammer E, Carr GJ, Wendler K, Rawlings JM, Belanger SE, Braunbeck T. Is the fish embryo toxicity test (FET) with the zebrafish (Danio rerio) a potential alternative for the fish acute toxicity test? Comp Biochem Physiol Part C, Pharmacol Toxicol Endocrinol 2009;149:196-209.

Law RJ. Petroleum hydrocarbon analyses conducted following the wreck of the supertanker Amoco Cadiz. Mar Pollut Bull 1978a;9:293-296.

Law RJ. Determination of petroleum hydrocarbons in water, fish and sediments following the Ekofisk blow-out. Mar Pollut Bull 1978b;9:321-324.

Lawrence A, Hemingway K. Effects of pollution on fish, molecular effects and population responses.

Lee RF, Anderson JW. Significance of cytochrome P450 system responses and levels of bile fluorescent aromatic compounds in marine wildlife following oil spills. Mar Pollut Bull 2005;50:705-723.

MacPhail RC, Brooks J, Hunter DL, Padnos B, Irons TD, Padilla S. Locomotion in larval zebrafish: Influence of time of day, lighting and ethanol. Neurotoxicology 2009;30:52-58. 
Martinez-Gomez C, Vethaak AD, Hylland K, Burgeot T, Köhler A, Lyons BP, Thain J, Gubbins MJ, Davies IM. A guide to toxicity assessment and monitoring effects at lower levels of biological organization following marine oil spills in European waters. J Mar Sci 2010;67:1105-1118.

Marty GD, Hose JE, McGurk MD, Brown ED, Hinton DE. Histopathology and cytogenetic evaluation of Pacific herring larvae exposed to petroleum hydrocarbons in the laboratory or in Prince William Sound, Alaska, after the $<\mathrm{I}>$ Exxon Valdez $</ \mathrm{I}>$ oil spill. Can $\mathrm{J}$ Fish Aquat Sci 1997;54:1846-1857.

Mazéas O, Budzinski $\mathrm{H}$. Solid-phase extraction and purification for the quantification of polycyclic aromatic hydrocarbon metabolites in fish bile. Anal Bioanal Chem 2005;383:985-990.

McGurk MD, Brown ED. Egg-larval mortality of Pacific herring in Prince William Sound, Alaska, after the Exxon Valdez oil spill. Can J Fish Aquat Sci 1996;55:2343-2354.

Meador JP, Stein JE, Reichert WL, Varanasi U. Bioaccumulation of polycyclic aromatic hydrocarbons by marine organisms. Rev Environ Contam Toxicol 1995;143:79-165.

Middaugh DP, Chapman PJ, Shelton ME. Responses of embryonic and larval inland silversides, Menidia beryllina, to a water-soluble fraction formed during biodegradation of artificially weathered Alaska North Slope crude oil. Arch Environ Contam Toxicol 1996;31:410 419.

Middaugh DP, Shelton ME, Mckenney CL, Cherr G, Chapman PJ, Courtney LA. Preliminary observations on responses of embryonic and larval pacific herring, Clupea pallasi, to neutral fraction biodegradation products of weathered Alaska north slope oil. Arch Environ Contam Toxicol 1998;196:188-196.

Milinkovitch T, Godefroy J, Théron M, Thomas-Guyon H. Toxicity of dispersant application: Biomarkers responses in gills of juvenile golden grey mullet (Liza aurata). Environ Pollut 2011a;159:2921-2928.

Milinkovitch T, Ndiaye A, Sanchez W, Le Floch S, Thomas-Guyon H. Liver antioxidant and plasma immune responses in juvenile golden grey mullet (Liza aurata) exposed to dispersed crude oil. Aquat Toxicol 2011b;101:155-164.

Muhling BA, Roffer MA, Lamkin JT, Ingram GW, Upton MA, Gawlikowski G, Muller-Karger F, Habtes S, Richards WJ. Overlap between Atlantic bluefin tuna spawning grounds and 
observed Deepwater Horizon surface oil in the northern Gulf of Mexico. Mar Pollut Bull 2012;64:679-687.

Nogueira P, Lourenço J, Rodriguez E, Pacheco M, Santos C, Rotchell JM, Mendo S. Transcript profiling and DNA damage in the European eel (Anguilla anguilla L.) exposed to 7,12dimethylbenz[a]anthracene. Aquat Toxicol 2009;94:123-30.

Norcross BL, Hose JE, Frandsen M, Brown ED. Distribution, abundance, morphological condition, and cytogenetic abnormalities of larval herring in Prince William Sound, Alaska, following the (Exxon Valdez) oil spill. Can J Fish Aquat Sci 1996;53:2376-2387.

NRC. Oil in the sea III : Inputs, fates, and effects. National Academies of Sciences, Washington DC. Report 2003; pp 176.

Oliveira M, Pacheco M, Santos M a. Organ specific antioxidant responses in golden grey mullet (Liza aurata) following a short-term exposure to phenanthrene. Sci Total Environ 2008;396:70-78.

van der Oost R, Beyer J, Vermeulen NPE. Fish bioaccumulation and biomarkers in environmental risk assessment: a review. Environ Toxicol Pharmacol 2003;13:57-149.

Örn S, Andersson P, Förlen L, Tysklind M, Norrgren L. The impact on reproduction of an orally administered mixture of selected PCBs in zebrafish (Danio rerio). Arch Environ Contam Toxicol 1998;35:52-57.

OSPAR. Guidelines for monitoring the environmental impact of offshore oil and gas activities. Oslo and Paris commissions, London. Report (in French) 2004; pp 20.

Padilla S, Hunter DL, Padnos B, Frady S, MacPhail RC. Assessing locomotor activity in larval zebrafish: Influence of extrinsic and intrinsic variables. Neurotoxicol Teratol 2011;33:624-630.

Péan S, Daouk T, Vignet C, Lyphout L, Leguay D, Loizeau V, Bégout M-L, Cousin X. Longterm dietary-exposure to non-coplanar PCBs induces behavioral disruptions in adult zebrafish and their offspring. Neurotoxicol Teratol 2013;39:45-56.

Perrichon P, Le Bihanic F, Bustamante P, Le Menach K, Budzinski H, Cachot J, Cousin X. Influence of sediment composition on PAH toxicity using zebrafish (Danio rerio) and Japanese medaka (Oryzias latipes) embryo-larval assays. Environ Sci Pollut Res 2014;21:13703-13719. 
Pollino CA, Holdway DA. Toxicity testing of crude oil and related compounds using early Life stages of the crimson-spotted rainbowfish (Melanotaenia fluviatilis). Ecotoxicol Environ Saf 2002;52:180-189.

Rhodes S, Farwell A, Hewitt LM, Mackinnon M, Dixon DG. The effects of dimethylated and alkylated polycyclic aromatic hydrocarbons on the embryonic development of the Japanese medaka. Ecotoxicol Environ Saf 2005;60:247-258.

Rice SD, Thomas RE, Carls MG, Heintz RA, Alex C, Murphy ML, Short JW, Moles A, Wertheimer AC, Michael L. Impacts to pink salmon following the Exxon Valdez oil spill : persistence, toxicity, sensitivity, and controversy. Rev Fish Sci 2001;9:165-211.

Saeed T, Al-Mutairi M. Comparative composition of polycyclic aromatic hydrocarbons (PAHs) in the sea water-soluble fractions of different Kuwaiti crude oils. Adv Environ Res 2000;4:141-145.

Schneider C a, Rasband WS, Eliceiri KW. NIH Image to ImageJ: 25 years of image analysis. Nat Methods 2012;9:671-675.

Scott J, Incardona JP, Pelkki K, Shepardson S, Hodson P V. AhR2-mediated, CYP1Aindependent cardiovascular toxicity in zebrafish (Danio rerio) embryos exposed to retene. Aquat Toxicol 2011;101:165-174.

Singer MM, Aurand D, Bragin GE, Clark JR, Coelho GM, Sowby ML. Standardization of the preparation and quantitation of water-accommodated fractions of petroleum for toxicity testing. Mar Pollut Bull 2000;40:1007-1016.

Strmac M, Oberemm A, Braunbeck T. Effects of sediment eluates and extracts from differently polluted small rivers on zebrafish embryos and larvae. J Fish Biol 2002;61:24-38.

Sun Y, Yu H, Zhang J, Yin Y, Shi H, Wang X. Bioaccumulation, depuration and oxidative stress in fish Carassius auratus under phenanthrene exposure. Chemosphere 2006;63:1319-27.

Tilseth S, Solberg TS, Westrheim K. Sublethal effects of the Water-Soluble Fraction of Ekofisk crude oil on the early larval stages of cod (Gadus morhua L.). Mar Environ Res 1984;11:1-16.

Tronczynski J, Munschy C, Héas-Moisan K, Guiot N, Truquet I, Olivier N, Men S, Furaut A. Contamination of the Bay of Biscay by polycyclic aromatic hydrocarbons (PAHs) following the T/V "Erika” oil spill. Aquat Living Resour 2004;259:243-259. 
Turcotte D, Akhtar P, Bowerman M, Kiparissis Y, Brown RS, Hodson P V. Measuring the toxicity of alkyl-phenanthrenes to early life stages of medaka (Oryzias latipes) using partition-controlled delivery. Environ Toxicol Chem 2011;30:487-495.

Usenko CY, Robinson EM, Usenko S, Brooks BW, Bruce ED. PBDE developmental effects on embryonic zebrafish. Environ Toxicol Chem 2011;30:1865-1872.

Varanasi U, Reichert WL, Stein JE, Brown DW, Sanborn HR. Bioavailability and biotransformation of aromatic hydrocarbons in benthic organisms exposed to sediment from an urban estuary. Environ Sci Technol 1985;19:836-841.

Wessel N, Ménard D, Pichavant-Rafini K, Ollivier H, Le Goff J, Burgeot T, Akcha F. Genotoxic and enzymatic effects of fluoranthene in microsomes and freshly isolated hepatocytes from sole (Solea solea). Aquat Toxicol 2012;108:33-41.

Xue W, Warshawsky D. Metabolic activation of polycyclic and heterocyclic aromatic hydrocarbons and DNA damage: a review. Toxicol Appl Pharmacol 2005;206:73-93.

Zar JH. Biostatistical analysis, 5th ed. Pe. Upper Saddle River, New Jersey 


\section{Figure captions}

Fig. 1. Experimental design of zebrafish embryo-larval assay.

Fig. 2. Zebrafish embryo-larval viability and hatching rates following BAL WAF (A, C) and HFO WAF (B, D) exposures. Arrow indicates time point from which significant differences were observed between HFO_100\% WAF and others concentrations. Letters denote significant differences between WAF concentrations at different exposure times (Chi-square, $p<0.05$ ).

Fig. 3. PhotoMotor Response measured in $120 \mathrm{hpf}$ zebrafish larvae after exposure to (A) BAL WAF and (B) HFO WAF. Means \pm SEM distance moved of larvae for each 5-min period of light/dark challenge. Lower and upper cases denote significant differences between WAF concentrations and light/dark periods (Light On (1), Ligh Off and Light On (2)) respectively (RANOVA, $\mathrm{p}<0.05)$.

Fig. 4. Heartbeat measured in 120 hpf zebrafish larvae after exposure to both BAL and HFO WAFs. Values are expressed in beat. $\mathrm{min}^{-1}$. No significant difference was observed after BAL WAF exposure (N-ANOVA, $\mathrm{p}>0.05)$. Asterisks denote significant differences with Control in HFO WAF exposure $(\mathrm{KW}, * * * \mathrm{p}<0.001)$.

Fig. 5. In vivo measurement of EROD activity in WAF-exposed larvae at the end of exposure (96 hpf). Values are expressed in response factor compared to respective Control group. Asterisks denote significant differences with respective Control. Dark traits denote significant differences between WAF concentrations (N-ANOVA, ${ }^{*} \mathrm{p}<0.05, * * \mathrm{p}<0.01$ and $\left.* * * \mathrm{p}<0.001\right)$.

Fig. 6. DNA strand breaks (\% tail DNA) measured in 24 hpf zebrafish embryos exposed to (A) BAL WAF and (B) HFO WAF by the comet assay. Values are means $\pm 95 \%$ confidence interval. Letters denote significant differences between BAL WAF concentrations (N-ANOVA, $\mathrm{p}<0.05$, $\mathrm{n}=3$ samples/300 nuclei). 
Fig. 7. Concentrations of PAH-metabolites (OHPAHs) measured in larvae at the end of exposure (96 hpf) for (A) BAL WAF and (B) HFO WAF. Values are means \pm SEM. n.d.: no detected. Stars denote significant differences compared to the Control. OHNaph: hydroxynaphthalenes; 2OHBi: 2-hydroxybiphenyl, OHPhe: hydroxyphenanthrenes, 3-OHFluo: 3-hydroxyfluoranthene, 1-OHPyr: 1-hydroxypyrene, 1-OHChrys: 1-hydroxychrysene, OHBaP: hydroxybenzo[a]pyrene. 
Table 1

Target compounds (ng. $\mathrm{L}^{-1}$ ) measured in water-accommodated fractions from Brut Arabian Light oil and Erika heavy fuel oil during zebrafish exposures. Values are means \pm SEM of both chemical replicates.

\begin{tabular}{|c|c|c|c|c|c|c|c|c|c|}
\hline \multirow[b]{2}{*}{ Compounds } & \multirow[b]{2}{*}{$\begin{array}{l}\text { Molecular } \\
\text { Weight }\left(\mathrm{g} \cdot \mathrm{mol}^{-1}\right)\end{array}$} & \multicolumn{4}{|c|}{ Concentration (ng. $\left.\mathrm{L}^{-1}\right)$ in brut Arabian light oil WAF } & \multicolumn{4}{|c|}{ Concentration $\left(\right.$ ng. $\left.\mathrm{L}^{-1}\right)$ in Erika heavy fuel oil WAF } \\
\hline & & Control & $1 \%$ & $10 \%$ & $100 \%$ & Control & $10 \%$ & $50 \%$ & $100 \%$ \\
\hline Naphthalene* & 128 & $\overline{2.2}$ & $159.8 \pm 66.2$ & $683.4 \pm 28.5$ & $5187.2 \pm 173.3$ & 1.4 & $561.4 \pm 29.4$ & $2916.2 \pm 488.7$ & $5394.1 \pm 146.4$ \\
\hline 1-Methylnaphthalene & 142 & 1.8 & $803.8 \pm 357.7$ & $3472.0 \pm 12.9$ & $25624.6 \pm 1241.6$ & 1.1 & $2278.7 \pm 172.1$ & $10583.3 \pm 2587.4$ & $45176.9 \pm 18810.7$ \\
\hline 2-Methylnaphthalene & 142 & 1.8 & $636.1 \pm 296.5$ & $2898.0 \pm 55.9$ & $22302.2 \pm 1049.1$ & 0.7 & $3753.0 \pm 265.3$ & $17989.0 \pm 4373.2$ & $34014.2 \pm 791.3$ \\
\hline$\sum$ Dimethylnapththalene & 156 & 29.5 & $2400.3 \pm 1023.0$ & $12074.8 \pm 110.8$ & $62915.5 \pm 4526.2$ & n.d. & $9924.9 \pm 436.0$ & $48633.3 \pm 11918.8$ & $88902.8 \pm 3404.2$ \\
\hline$\sum$ Trimethylnapththalene & 170 & 51.1 & $1546.1 \pm 638.7$ & $7201.5 \pm 7.0$ & $39626.7 \pm 3530.4$ & n.d. & $5211.6 \pm 253.3$ & $26215.0 \pm 5908.9$ & $49234.8 \pm 2468.4$ \\
\hline$\sum$ Tetramethylnaphthalene & 184 & n.d. & $317.9 \pm 124.6$ & $1851.3 \pm 20.9$ & $8971.7 \pm 1195.3$ & n.d. & $1388.5 \pm 128.2$ & $6540.5 \pm 1437.5$ & $12949.0 \pm 572.9$ \\
\hline Acenaphtylene* & 152 & n.d. & n.d. & n.d. & n.d. & n.d. & $8.4 \pm 0.6$ & $22.2 \pm 1.8$ & $86.1 \pm 31.3$ \\
\hline Acenaphtene* & 154 & 0.8 & n.d. & $11.8 \pm 1.5$ & $64.3 \pm 6.1$ & n.d. & $90.2 \pm 9.0$ & $437.9 \pm 103.0$ & $1302.4 \pm 449.6$ \\
\hline Fluorene* & 166 & 0.6 & $14.7 \pm 5.7$ & $64.7 \pm 1.1$ & $398.5 \pm 32.5$ & 0.6 & $77.0 \pm 7.1$ & $375.7 \pm 79.6$ & $634.4 \pm 59.1$ \\
\hline Phenanthrene* & 178 & 2.6 & $22.8 \pm 8.1$ & $67.4 \pm 0.2$ & $383.4 \pm 36.6$ & 1.7 & $566.6 \pm 277.0$ & $941.9 \pm 168.3$ & $3531.0 \pm 1504.8$ \\
\hline 1-Methylphenanthrene & 192 & 2.3 & $30.6 \pm 12.4$ & $34.6 \pm 1.7$ & $183.6 \pm 15.1$ & 0.9 & $307.2 \pm 157.9$ & $326.2 \pm 50.8$ & $1402.0 \pm 570.9$ \\
\hline 2-Methylphenanthrene & 192 & 0.4 & $8.2 \pm 3.5$ & $22.7 \pm 1.8$ & $156.3 \pm 14.9$ & 0.7 & $118.3 \pm 28.1$ & $570.4 \pm 83.8$ & $2454.7 \pm 989.2$ \\
\hline 3-Methylphenanthrene & 192 & 0.3 & $7.0 \pm 3.1$ & $20.7 \pm 0.3$ & $116.3 \pm 1.6$ & 0.3 & $292.1 \pm 142.4$ & $484.9 \pm 70.2$ & $2078.1 \pm 835.6$ \\
\hline$\sum$ Dimethylphenanthrene & 206 & 5.5 & $68.3 \pm 26.7$ & $79.5 \pm 1.3$ & $419.7 \pm 28.7$ & n.d. & $382.2 \pm 104.5$ & $869.5 \pm 219.2$ & $4062.6 \pm 1593.8$ \\
\hline$\sum$ Trimethylphenanthrene & 220 & 3.8 & n.d. & $23.5 \pm 1.9$ & $128.5 \pm 15.7$ & n.d. & $473.3 \pm 278.2$ & $384.2 \pm 115.6$ & $1266.1 \pm 504.7$ \\
\hline Anthracene* & 178 & n.d. & n.d. & $17.2 \pm 10.1$ & $7.2 \pm 0.8$ & n.d. & $26.5 \pm 3.0$ & $118.9 \pm 18.5$ & $169.9 \pm 2.3$ \\
\hline 2-Methylanthracene & 192 & 0.3 & n.d. & n.d. & n.d. & n.d. & $77.5 \pm 39.5$ & $99.9 \pm 12.3$ & $430.3 \pm 165.3$ \\
\hline $\begin{array}{l}{[9+4]-\text { Methylphenanthrene }+1 \text { - }} \\
\text { MethylAnthracene + 4,5-Mphenanthrene }\end{array}$ & 192 & 0.7 & $5.6 \pm 0.2$ & $48.2 \pm 0.9$ & $318.2 \pm 25.5$ & 0.3 & $233.3 \pm 114.7$ & $366.8 \pm 49.8$ & $1604.1 \pm 651.6$ \\
\hline Dibenzo[b,d]thiophene & 184 & 0.3 & $51.5 \pm 19.9$ & $240.0 \pm 0.2$ & $1503.7 \pm 133.5$ & 0.1 & $78.8 \pm 7.5$ & $368.7 \pm 73.6$ & $627.5 \pm 61.5$ \\
\hline 1-Methyldibenzothiophene & 198 & n.d. & $29.8 \pm 11.6$ & $150.3 \pm 2.0$ & $952.3 \pm 77.3$ & n.d. & $53.4 \pm 4.6$ & $246.3 \pm 37.0$ & $472.0 \pm 2.9$ \\
\hline 3,2-Methyldibenzothiophene & 198 & n.d. & $30.3 \pm 12.2$ & $137.5 \pm 1.7$ & $885.4 \pm 67.5$ & n.d. & $69.1 \pm 6.0$ & $305.4 \pm 42.0$ & $574.9 \pm 6.8$ \\
\hline 1-Methyldibenzothiophene & 198 & n.d. & $21.9 \pm 8.7$ & $98.4 \pm 2.6$ & $642.0 \pm 48.5$ & n.d. & $30.1 \pm 2.7$ & $129.5 \pm 20.4$ & $241.4 \pm 3.7$ \\
\hline 2,1-Dibenzonaphthothiophene & 234 & n.d. & n.d. & $1.1 \pm 0.2$ & $4.0 \pm 1.0$ & n.d. & $8.9 \pm 3.9$ & $19.7 \pm 6.8$ & $24.7 \pm 5.8$ \\
\hline Fluoranthene* & 202 & 0.5 & $1.7 \pm 0.2$ & $2.1 \pm 0.6$ & $7.8 \pm 2.5$ & 0.5 & $5.9 \pm 0.5$ & $21.9 \pm 2.0$ & $40.3 \pm 2.2$ \\
\hline Pyrene* & 202 & 0.3 & $1.3 \pm 0.2$ & $1.9 \pm 0.5$ & $5.2 \pm 0.7$ & 0.1 & $23.3 \pm 3.3$ & $93.2 \pm 12.6$ & $164.3 \pm 6.2$ \\
\hline Benzo[a]anthracene* & 228 & n.d. & n.d. & n.d. & $2.2 \pm 0.6$ & n.d. & $13.7 \pm 8.0$ & $11.6 \pm 3.5$ & $14.9 \pm 1.3$ \\
\hline Chrysene + Triphenylene* & 228 & 0.2 & $1.3 \pm 0.3$ & $0.6 \pm 0.01$ & $2.6 \pm 0.2$ & n.d. & $10.9 \pm 3.1$ & $31.7 \pm 10.1$ & $45.3 \pm 5.0$ \\
\hline ¿Methylchrysene & 242 & n.d. & n.d. & n.d. & n.d. & n.d. & $34.3 \pm 7.4$ & $89.4 \pm 43.6$ & $114.9 \pm 36.4$ \\
\hline Benzo $[\mathrm{b}+\mathrm{j}+\mathrm{k}]$ fluoranthene* & 252 & n.d. & n.d. & n.d. & n.d. & n.d. & $1.5 \pm 0.3$ & $2.3 \pm 1.2$ & $2.5 \pm 0.9$ \\
\hline Benzo[e]pyrene & 252 & n.d. & n.d. & n.d. & n.d. & n.d. & $1.5 \pm 0.7$ & $3.9 \pm 2.4$ & $3.5 \pm 1.6$ \\
\hline Benzo[a]pyrene* & 252 & n.d. & n.d. & n.d. & n.d. & n.d. & $0.9 \pm 0.4$ & $2.3 \pm 1.5$ & $1.6 \pm 0.8$ \\
\hline Perylene & 252 & n.d. & n.d. & n.d. & n.d. & n.d. & $0.7 \pm 0.0$ & $1.9 \pm 0.0$ & $1.0 \pm 0.5$ \\
\hline Indeno[1,2,3-cd]pyrene* & 276 & n.d. & n.d. & n.d. & n.d. & n.d. & n.d. & n.d. & n.d. \\
\hline Benzo[g,h,i]perylene* & 276 & n.d. & n.d. & n.d. & n.d. & n.d. & $2.0 \pm 0.0$ & $3.8 \pm 0.0$ & $5.3 \pm 0.0$ \\
\hline Dibenzo[a,h]+[a,c]anthracene* & 278 & n.d. & n.d. & n.d. & n.d. & n.d. & n.d. & n.d. & $1.2 \pm 0.0$ \\
\hline
\end{tabular}

* Priority contaminants selected by the US Environmental Protection Agency (EPA)

n.d. $<$ detection limit. 
Table 2

Specific primer sequences for the 12 target genes measured by real-time PCR.

\begin{tabular}{|c|c|c|}
\hline Target gene & Accession Number & Primer $\left(5^{\prime} \rightarrow 3^{\prime}\right)$ \\
\hline \multirow[t]{2}{*}{ gapdh } & $\mathrm{BC} 083506$ & GTGGAGTCTACTGGTGTCTTC $^{a}$ \\
\hline & & GTGCAGGAGGCATTGCTTACA $^{\mathrm{b}}$ \\
\hline \multirow[t]{2}{*}{ eef1 } & NM_131263.1 & CAGCTGATCGTTGGAGTCAA ${ }^{\mathrm{a}}$ \\
\hline & & TGTATGCGCTGACTTCCTTG ${ }^{\mathrm{b}}$ \\
\hline \multirow[t]{2}{*}{ g6pd } & BM_182602 & GTCCCGAAAGGCTCCACTC ${ }^{\mathrm{a}}$ \\
\hline & & CCTCCGCTTTCCTCTC $^{\mathrm{b}}$ \\
\hline \multirow[t]{2}{*}{ Bactin } & NM_131031 & CCCAGACATCAGGGAGTGAT $^{\mathrm{a}}$ \\
\hline & & CACAATACCGTGCTCAATGG $^{\mathrm{b}}$ \\
\hline \multirow[t]{2}{*}{ cypla } & ВС094977 & GACAGGCGCTCCTAAAACAG $^{\mathrm{a}}$ \\
\hline & & CTGAACGCCAGACTCTTTCC ${ }^{\mathrm{b}}$ \\
\hline \multirow[t]{2}{*}{$a h r 2$} & NM_131264 & GCCTGGGATAAAGGAGGAAG $^{\mathrm{a}}$ \\
\hline & & CAGCTCCACCTGTCCAAAT $^{\mathrm{b}}$ \\
\hline \multirow[t]{2}{*}{ cat } & NM_130912 & CGCTTCTGTTTCCGTCTTTC ${ }^{a}$ \\
\hline & & CCCTGAGCATTGACCAGTTT $^{\mathrm{b}}$ \\
\hline \multirow[t]{2}{*}{$\operatorname{sod}(\mathrm{Cu} / \mathrm{Zn})$} & ВC055516 & GTTTCCACGTCCATGCTTTT ${ }^{\mathrm{a}}$ \\
\hline & & CGGTCACATTACCCAGGTCT $^{b}$ \\
\hline \multirow[t]{2}{*}{$\operatorname{sod}(M n)$} & CB923500 & GGCCAAGGGTGATGTGAC ${ }^{a}$ \\
\hline & & ACGCTTTATGGCCTCCAAC ${ }^{\mathrm{b}}$ \\
\hline \multirow[t]{2}{*}{ gpx4 } & NM_001007282.1 & AGGATCCAAGTGTGGTGGAG ${ }^{\mathrm{a}}$ \\
\hline & & GGGGTTTCCAAACAAACCTT ${ }^{\mathrm{b}}$ \\
\hline \multirow[t]{2}{*}{$p 53$} & NM_131327.1 & GCTTGTCACAGGGGTCATTT ${ }^{\mathrm{a}}$ \\
\hline & & ACAAAGGTCCCAGTGGAGTG ${ }^{\mathrm{b}}$ \\
\hline \multirow[t]{2}{*}{$b a x$} & AF231015 & GGAGATGAGCTGGATGGAAA $^{\mathrm{a}}$ \\
\hline & & GAAAAGCGCCACAACTCTTC \\
\hline
\end{tabular}

${ }^{a}$ Forward primer, ${ }^{b}$ Reverse primer

gapdh: glyceraldehyde-3-phosphate dehydrogenase ; eef1: eukaryotic elongation factor ; g6pd: glucose-6-phosphate dehydrogenase ; Bactin: beta-actin ; cypla: cytochrome P4501A ; ahr2: aryl hydrocarbon receptor 2 ; cat: catalase ; sod(Cu/Zn): Cu/Zn-superoxide dismutase ; sod(Mn): Mn-superoxide dismutase ; gpx4: glutathione peroxidase 4 ; p53: bcl-2binding component 3 ; bax: bcl-2-associates X protein. 
Table 3

Number of total individuals sampled for different chemical and biological analyses. The number into brackets corresponds to the number of replicates used.

\begin{tabular}{|c|c|c|c|c|c|c|c|c|c|}
\hline \multirow[b]{2}{*}{ Sampling point } & \multirow[b]{2}{*}{ Toxicity endpoints } & \multicolumn{4}{|c|}{ BAL WAF } & \multicolumn{4}{|c|}{ HFO WAF } \\
\hline & & Control & $1 \%$ & $10 \%$ & $100 \%$ & Control & $10 \%$ & $50 \%$ & $100 \%$ \\
\hline $0-15 \mathrm{dpf}$ & Survival & $150(5)$ & $150(5)$ & $150(5)$ & $150(5)$ & $150(5)$ & $150(5)$ & $150(5)$ & $150(5)$ \\
\hline $48-96 \mathrm{hpf}$ & Hatching success & $150(5)$ & $150(5)$ & $150(5)$ & $150(5)$ & $150(5)$ & $150(5)$ & $150(5)$ & $150(5)$ \\
\hline $96 \mathrm{hpf}$ & Morphological analyses & $47(5)$ & $44(5)$ & $46(5)$ & $45(5)$ & $37(5)$ & $55(5)$ & $50(5)$ & $45(5)$ \\
\hline $120 \mathrm{hpf}$ & PMR analyses & $43(5)$ & $35(5)$ & $40(5)$ & $39(5)$ & $46(5)$ & $44(5)$ & $43(5)$ & $20(5)$ \\
\hline $120 \mathrm{hpf}$ & Heartbeat & $16(5)$ & $15(5)$ & $19(5)$ & $16(5)$ & $18(5)$ & $20(5)$ & $20(5)$ & $23(5)$ \\
\hline $96 \mathrm{hpf}$ & EROD activity & $25(5)$ & $25(5)$ & $25(5)$ & $25(5)$ & $25(5)$ & $25(5)$ & $25(5)$ & $25(5)$ \\
\hline $24 \mathrm{hpf}$ & DNA damage & $5(3)^{\mathrm{a}}$ & $5(3)^{\mathrm{a}}$ & $5(3)^{\mathrm{a}}$ & $5(3)^{\mathrm{a}}$ & $5(3)^{\mathrm{a}}$ & $5(3)^{\mathrm{a}}$ & $5(3)^{\mathrm{a}}$ & $5(3)^{\mathrm{a}}$ \\
\hline $96 \mathrm{hpf}$ & Gene transcription & $20(5)^{\mathrm{ab}}$ & $20(5)^{\mathrm{ab}}$ & $20(5)^{\mathrm{ab}}$ & $20(5)^{\mathrm{ab}}$ & $20(5)^{\mathrm{ab}}$ & $20(5)^{\mathrm{ab}}$ & $20(5)^{\mathrm{ab}}$ & $20(5)^{\mathrm{ab}}$ \\
\hline $120 \mathrm{hpf}$ & PAHs metabolites & $50(3)^{\mathrm{ab}}$ & $50(3)^{\mathrm{ab}}$ & $50(3)^{\mathrm{ab}}$ & $50(3)^{\mathrm{ab}}$ & $50(3)^{\mathrm{ab}}$ & $50(3)^{\mathrm{ab}}$ & $50(3)^{\mathrm{ab}}$ & $50(3)^{\mathrm{ab}}$ \\
\hline
\end{tabular}

${ }^{a}$ Individuals pooled for analysis; ${ }^{\mathrm{b}}$ The replicate number corresponds to replicates of experiment 
Table 4

Summarized of aromatic compounds (ng. $\mathrm{L}^{-1}$ ) measured in water accommodated-fraction from Brut Arabian Light oil (WAF BAL) and Erika Heavy Fuel oil (WAF HFO) during zebrafish exposures. Values are means \pm SEM of both chemical replicates.

\begin{tabular}{|c|c|c|c|c|c|c|c|c|c|c|}
\hline & & \multicolumn{9}{|c|}{ Concentrations $\left(\mathrm{ng} . \mathrm{L}^{-1}\right)$} \\
\hline & & $\overline{\Sigma \text { TPAHs }}$ & $\Sigma 16 \mathrm{PAHs}$ & $\Sigma$ LMW PAHs & $\Sigma$ HMW PAHs & $\sum$ sulpPAHs & $\Sigma$ MNaph & $\Sigma$ MPhe & $\Sigma$ MDBT & $\Sigma$ MChrys \\
\hline \multirow{4}{*}{ BAL } & Control & 105.8 & 7.1 & 6.2 & 0.9 & 0.3 & 84.1 & 13.0 & n.d. & n.d. \\
\hline & $1 \%$ & $6158.5 \pm 3705.4$ & $201.6 \pm 75.0$ & $197.3 \pm 75.0$ & $4.3 \pm 0.1$ & $51.5 \pm 19.9$ & $5704.2 \pm 2440.4$ & $119.7 \pm 77.4$ & $81.1 \pm 32.7$ & n.d. \\
\hline & $10 \%$ & $29203.0 \pm 23.3$ & $849.0 \pm 22.3$ & $844.5 \pm 29.9$ & $4.5 \pm 1.1$ & $240.0 \pm 0.2$ & $20997.6 \pm 207.5$ & $209.2 \pm 7.9$ & $387.3 \pm 6.5$ & n.d. \\
\hline & $100 \%$ & $170808.9 \pm 4479.9$ & $6058.4 \pm 248.3$ & $6040.6 \pm 249.3$ & $17.8 \pm 1.1$ & $1503.7 \pm 133.5$ & $123440.7 \pm 11542.6$ & $1322.5 \pm 101.5$ & $2483.7 \pm 194.3$ & n.d. \\
\hline \multirow{4}{*}{ HFO } & Control & 8.4 & 4.3 & 4.3 & 3.7 & 0.1 & 1.8 & 2.2 & n.d. & n.d. \\
\hline & $10 \%$ & $26105.4 \pm 3527.6$ & $1388.3 \pm 341.7$ & $1330.1 \pm 324.8$ & $58.2 \pm 15.6$ & $78.8 \pm 7.5$ & $22556.7 \pm 1255.0$ & $1806.4 \pm 825.8$ & $161.5 \pm 17.2$ & $34.3 \pm 7.4$ \\
\hline & $50 \%$ & $119207.2 \pm 39521.7$ & $4886.5 \pm 890.8$ & $4812.8 \pm 859.9$ & $73.7 \pm 30.9$ & $368.7 \pm 73.6$ & $86367.1 \pm 26225.8$ & $3001.9 \pm 589.4$ & $700.9 \pm 106.2$ & $89.4 \pm 43.6$ \\
\hline & $100 \%$ & $257028.5 \pm 47230.7$ & $11158.8 \pm 2209.9$ & $10883.4 \pm 2193.5$ & $275.4 \pm 16.4$ & $627.7 \pm 61.5$ & $230277.6 \pm 26047.4$ & $12867.6 \pm 5145.8$ & $1313.0 \pm 19.2$ & $114.9 \pm 36.4$ \\
\hline
\end{tabular}

molecular weight PAHs based on the $\Sigma 16$ PAHs; $\Sigma$ sulfPAHs: sum of aromatic sulphurated compounds based on the $\Sigma 16$ PAHs; $\Sigma$ Mnaph: sum of MethylNaphtalenes; $\Sigma$ MPhe: sum of MethylPhenanthrenes; $\Sigma$ MDBT: sum of MethylDibenzothiophenes; $\Sigma$ MChrys: sum of MethylChrysenes.

n.d. $<$ detection limit. 
Table 5

Developmental endpoints for assessing toxicity and teratogenicity of both BAL and HFO WAFs on zebrafish larvae at the end of exposure (96 hpf). Biometric values are means \pm SEM and abnormalities values are percentages of total effective.

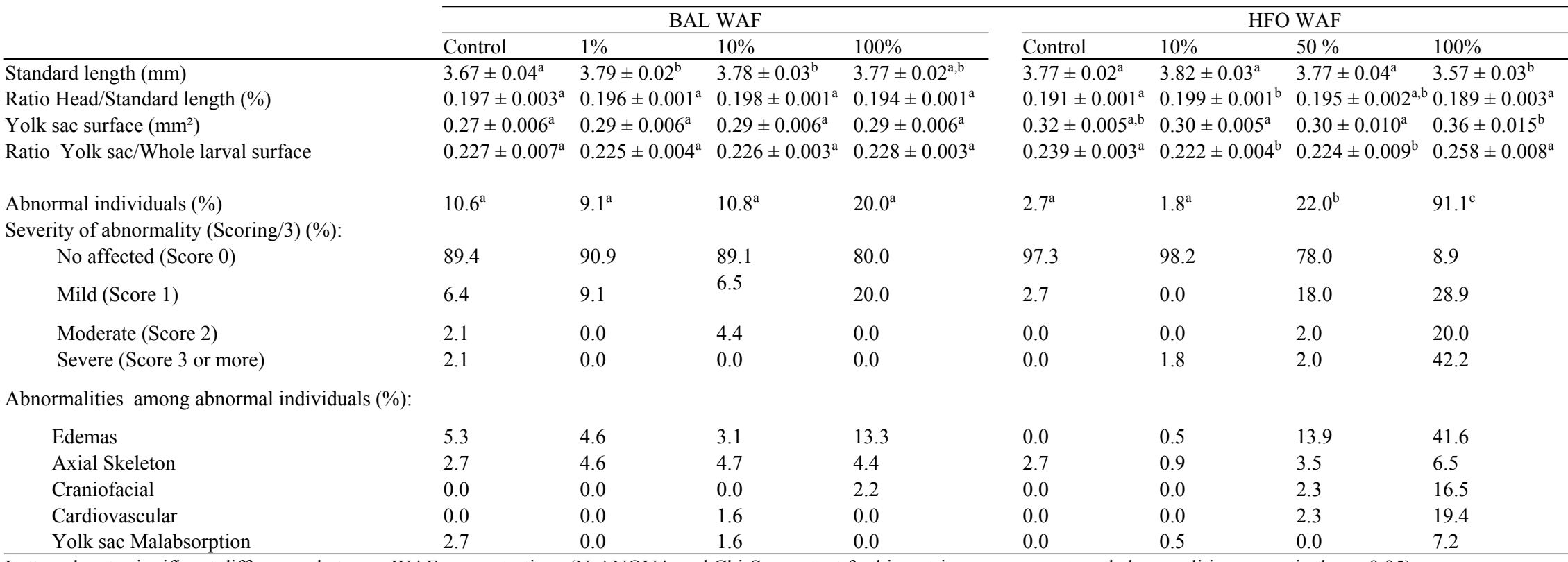

Letters denote significant differences between WAF concentrations (N-ANOVA and Chi-Square test for biometric measurements and abnormalities respectively, $\mathrm{p}<0.05$ ). 


\section{Table 6}

Relative mRNA expression ratio from the Control condition (Standard Error) of target genes in zebrafish larvae after 96 hours of WAFs exposures.

\begin{tabular}{|c|c|c|c|c|c|c|}
\hline & \multicolumn{3}{|c|}{$B A L W A F$} & \multicolumn{3}{|c|}{ HFO WAF } \\
\hline & $1 \%$ & $10 \%$ & $100 \%$ & $10 \%$ & $50 \%$ & $100 \%$ \\
\hline \multicolumn{7}{|l|}{ Detoxification } \\
\hline cypla & $1.166(0.993-1.443)$ & $1.266(1.041-1.535)^{* *}$ & $3.994(3.492-4.678)^{* *}$ & $2.041(1.176-6.440)^{* *}$ & $4.546(2.370-14.780)^{* *}$ & $8.308(4.242-24.222)^{* *}$ \\
\hline$a h r 2$ & $1.073(0.950-1.187)$ & $0.944(0.879-1.026)$ & $1.053(0.913-1.196)$ & $1.826(1.041-4.060)^{*}$ & $1.298(0.644-3.656)$ & $1.275(0.773-3.364)$ \\
\hline \multicolumn{7}{|c|}{ Oxidative stress } \\
\hline gpx4a & $1.081(0.975-1.257)$ & $1.257(1.076-1.450)^{* *}$ & $1.294(1.107-1.508)^{*}$ & $1.242(0.853-2.040)$ & $1.374(0.924-2.287)$ & $1.609(1.029-2.545)^{*}$ \\
\hline cat & $0.978(0.839-1.125)$ & $0.988(0.877-1.146)$ & $1.126(0.973-1.291)$ & $1.362(1.113-1.614)^{* *}$ & $1.420(1.217-1.649)^{* * *}$ & $1.252(1.022-1.474)^{*}$ \\
\hline $\operatorname{sod}(\mathrm{Cu} / \mathrm{Zn})$ & $1.138(1.023-1.258)^{*}$ & $1.183(1.064-1.323)^{*}$ & $1.239(1.101-1.410)^{*}$ & $1.204(0.826-1.663)$ & $1.388(0.985-1.937)^{*}$ & $1.626(1.038-2.575)^{*}$ \\
\hline $\operatorname{sod}(M n)$ & $1.058(0.979-1.169)$ & $1.113(1.020-1.226)$ & $1.191(1.088-1.312)^{*}$ & $1.088(0.932-1.294)$ & $1.003(0.839-1.261)$ & $1.385(1.106-1.932)^{*}$ \\
\hline \multicolumn{7}{|l|}{ Apoptosis } \\
\hline p53 & $1.083(0.999-1.181)$ & $1.074(0.952-1.220)$ & $1.142(1.069-1.210)^{* *}$ & $0.863(0.568-1.277)$ & $1.075(0.716-1.574)$ & $1.236(0.781-1.846)$ \\
\hline $\operatorname{bax}$ & $0.979(0.932-1.023)$ & $0.985(0.932-1.106)$ & $1.025(0.979-1.076)$ & $0.959(0.808-1.104)$ & $0.963(0.881-1.060)$ & $1.036(0.873-1.252)$ \\
\hline
\end{tabular}

Asterisks denote significant changes from respective Controls $\left({ }^{*} \mathrm{p}<0.05\right.$, ** $\mathrm{p}<0.01$ and $\left.{ }^{* * *} \mathrm{p}<0.001\right)$. 


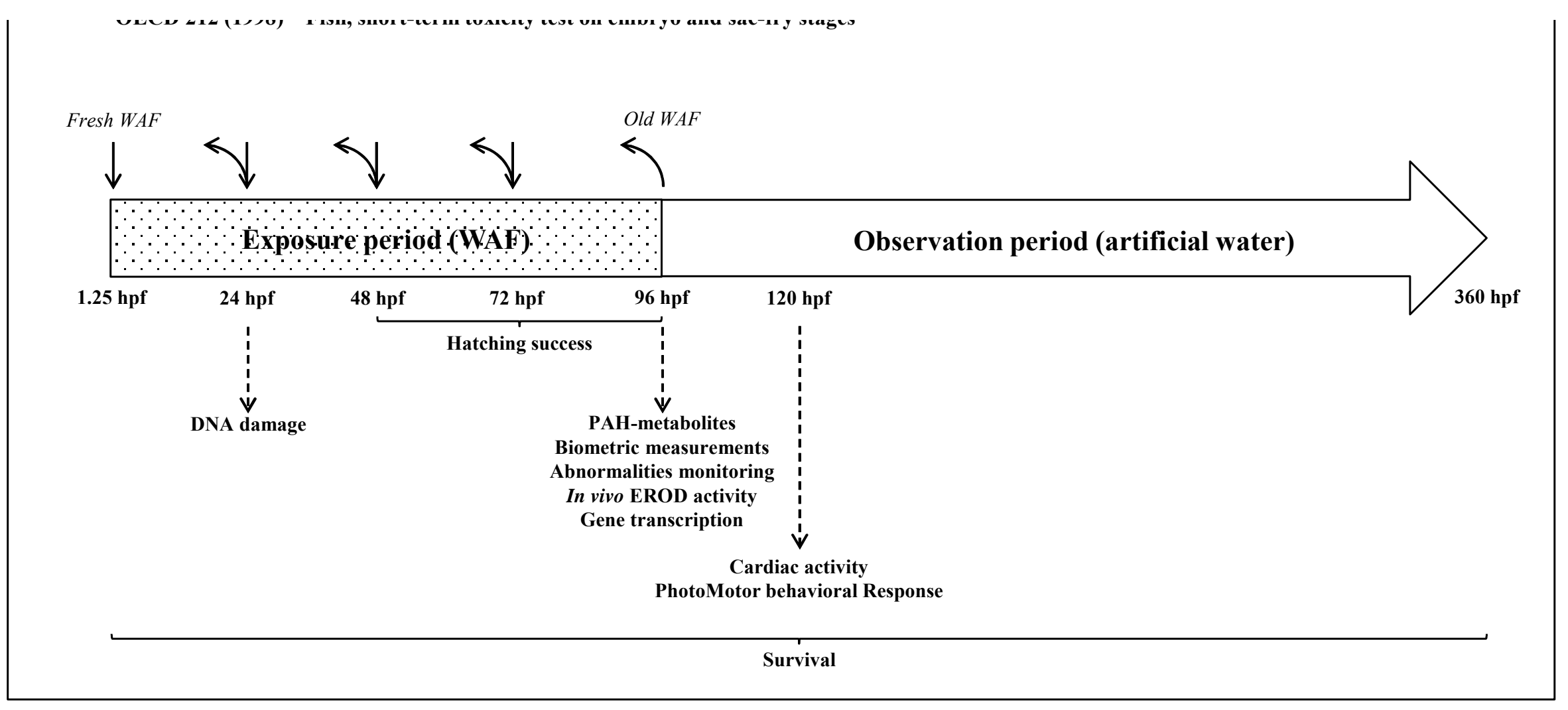




\section{FIGURE 2}

A

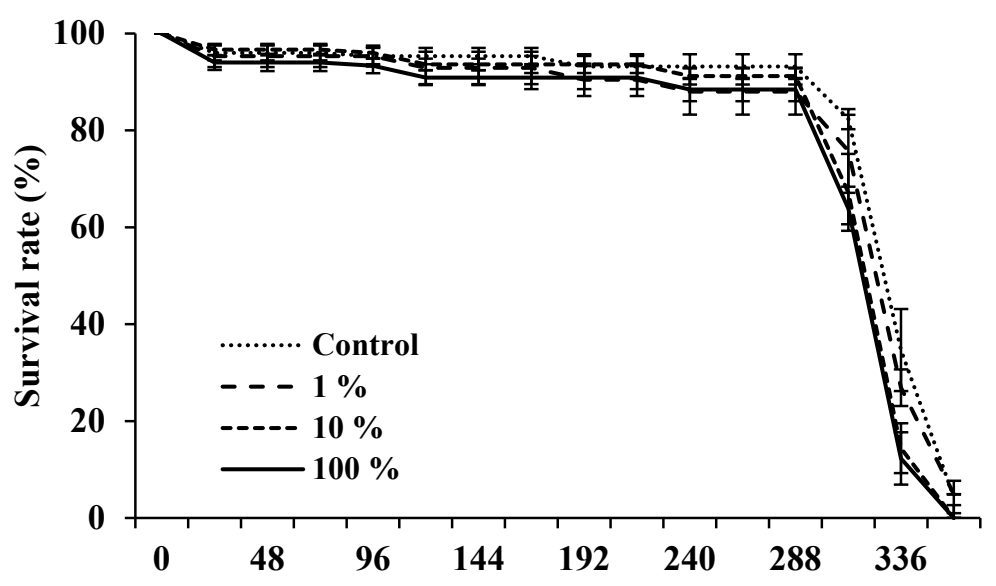

B

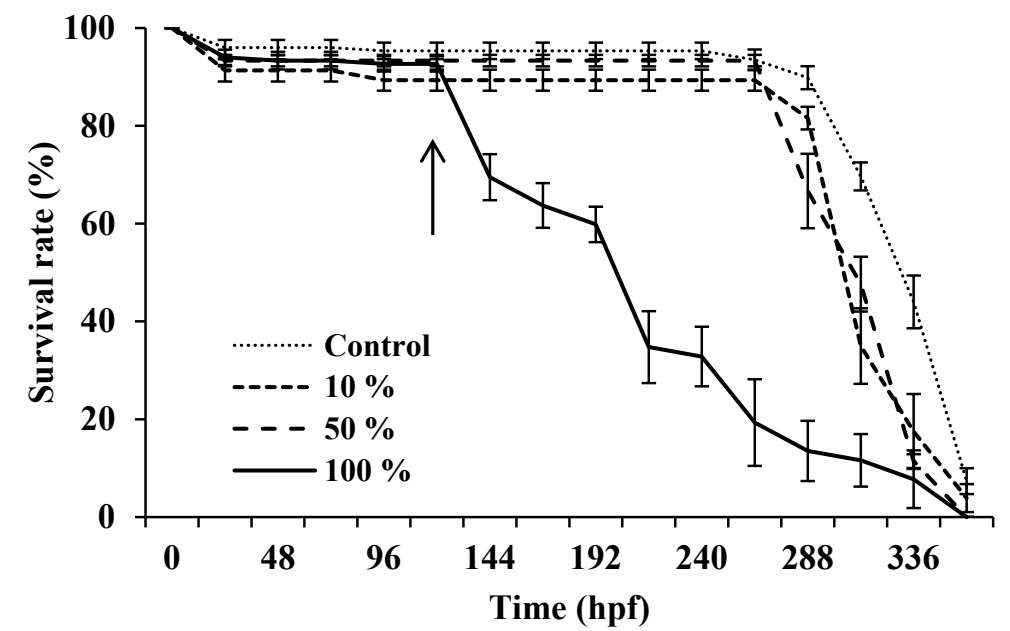

BAL

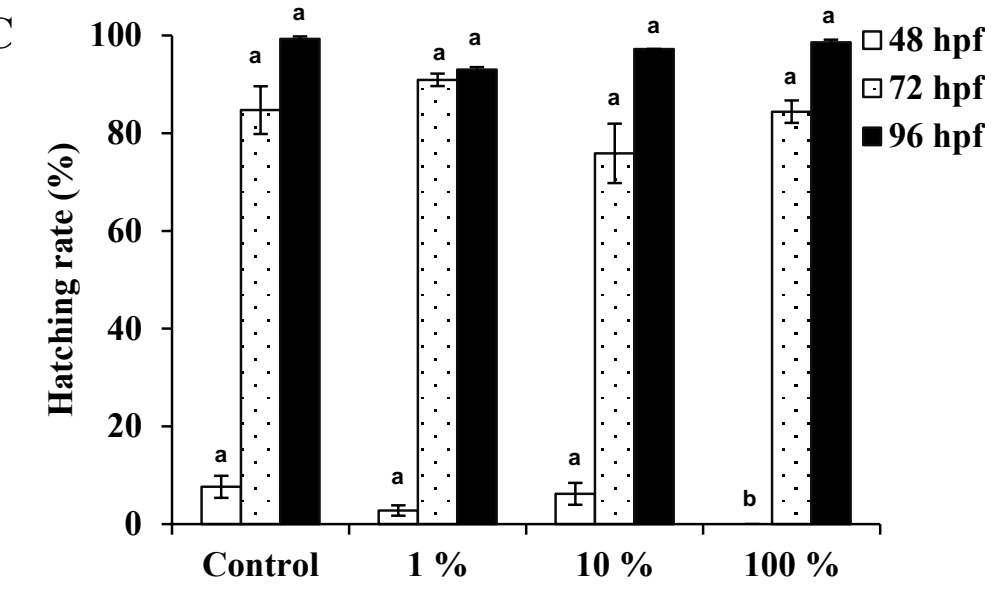

HFO

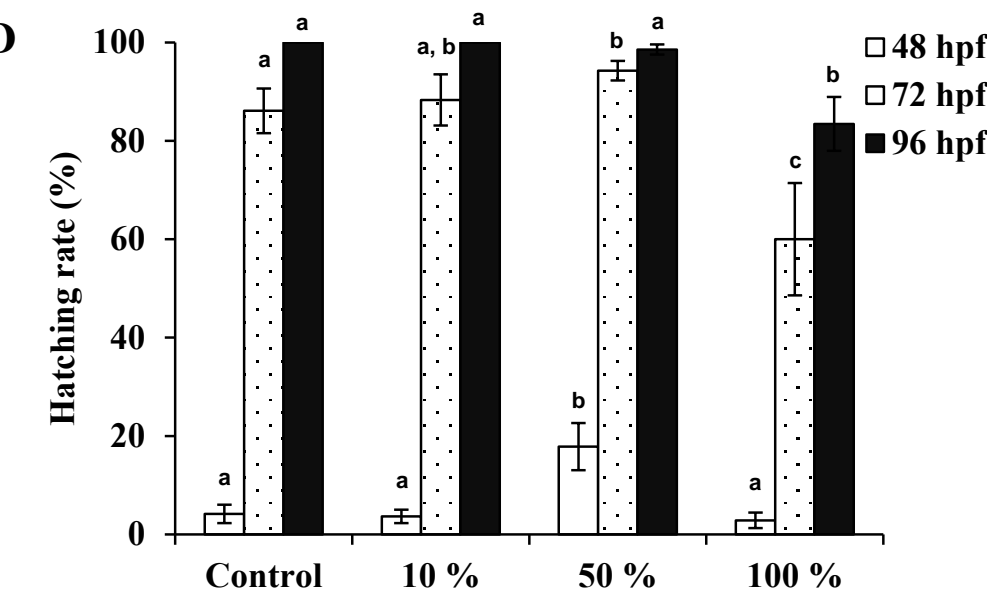




\section{FIGURE 3}
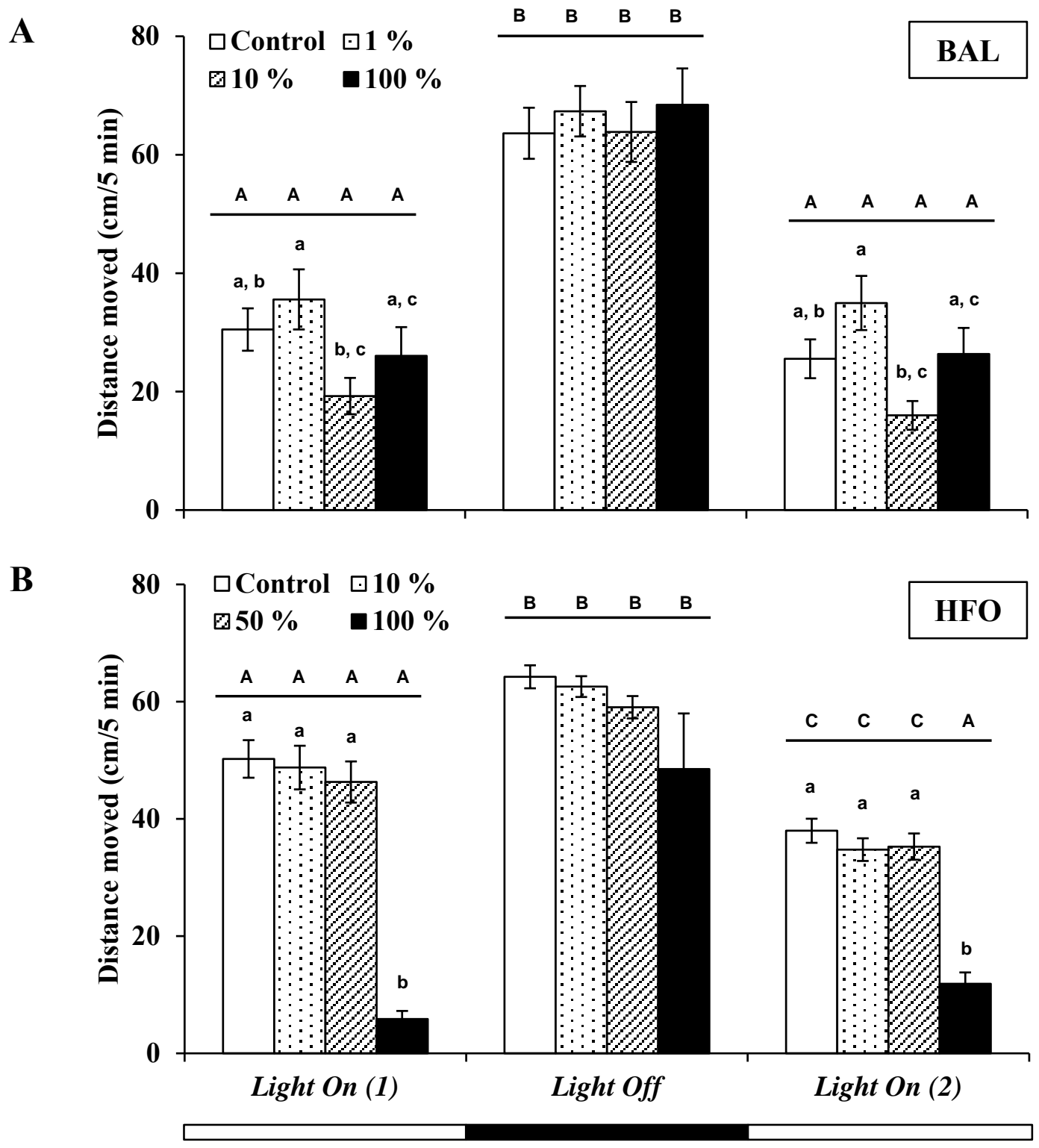


\section{FIGURE 4}

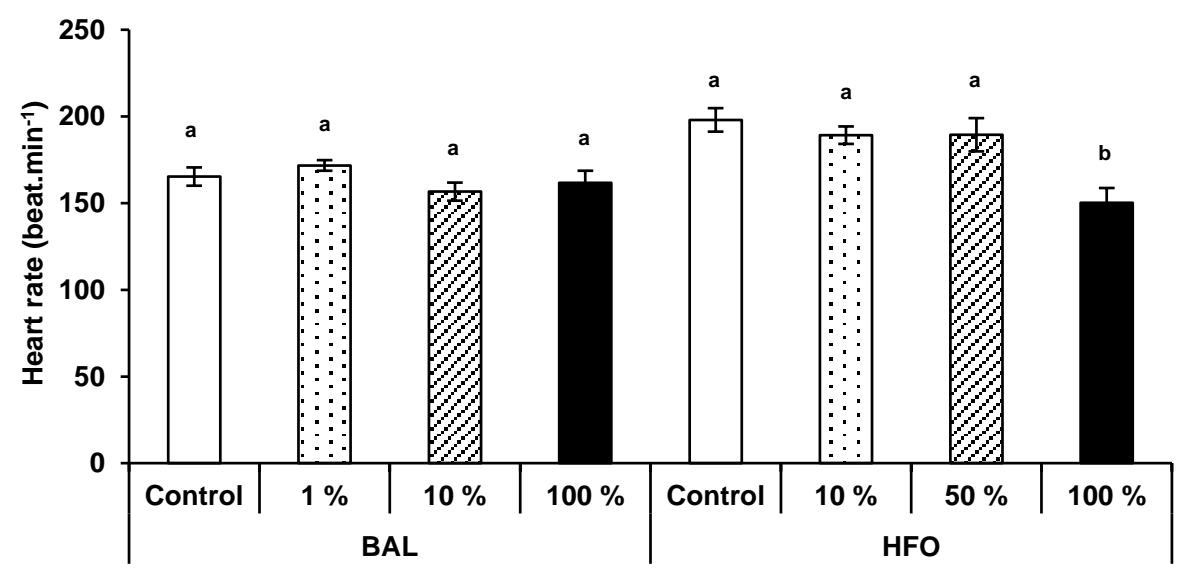




\section{FIGURE 5}

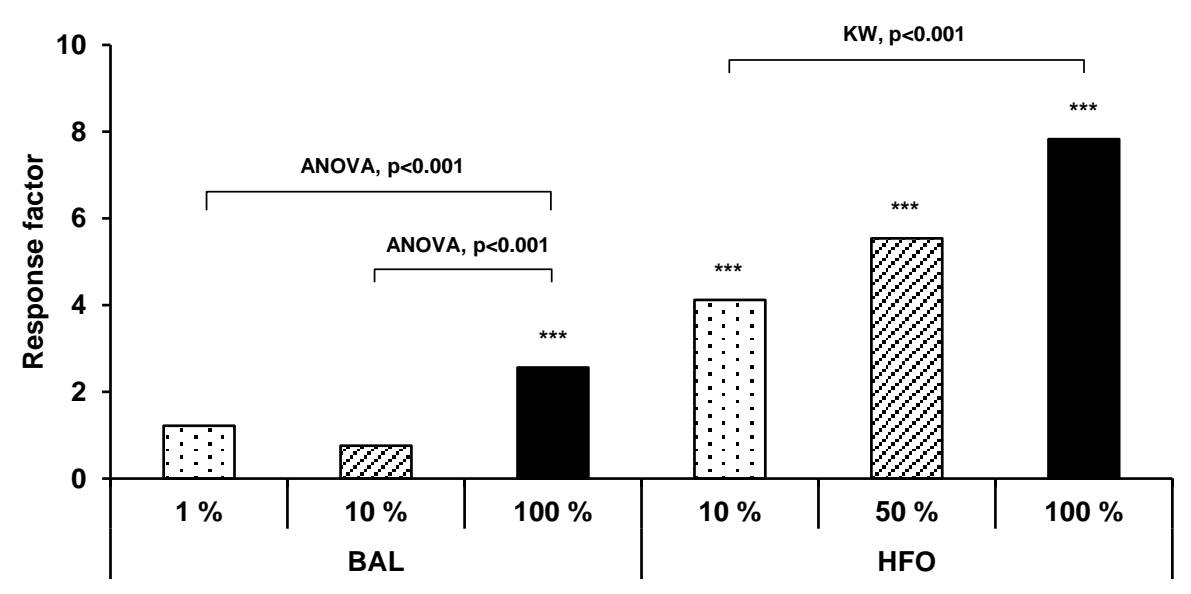




\section{FIGURE 6}

- Mean $\square$ Mean \pm SE I Mean $\pm 0,95$ Conf. Interval

A

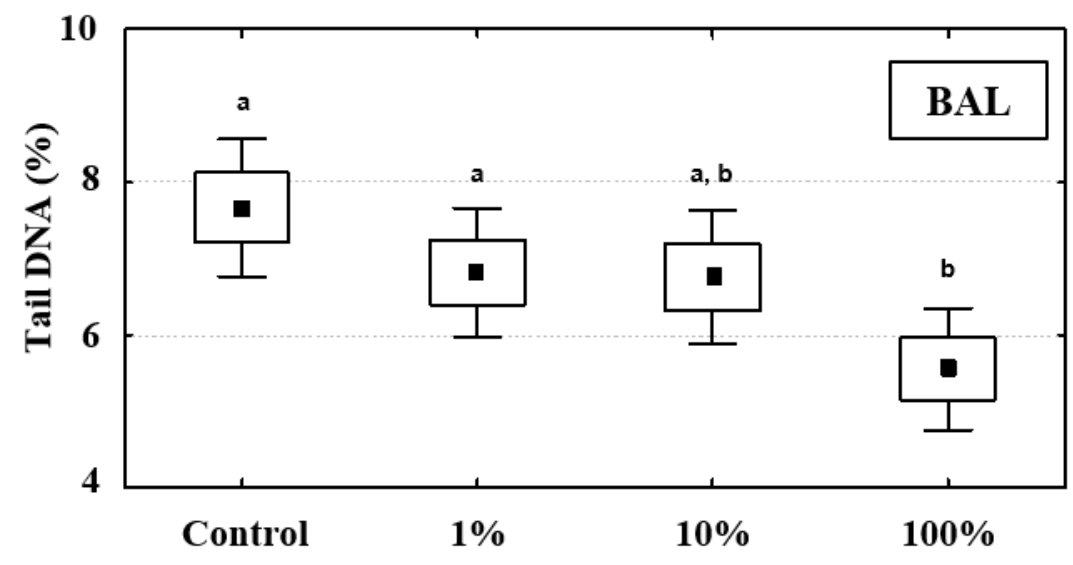

B

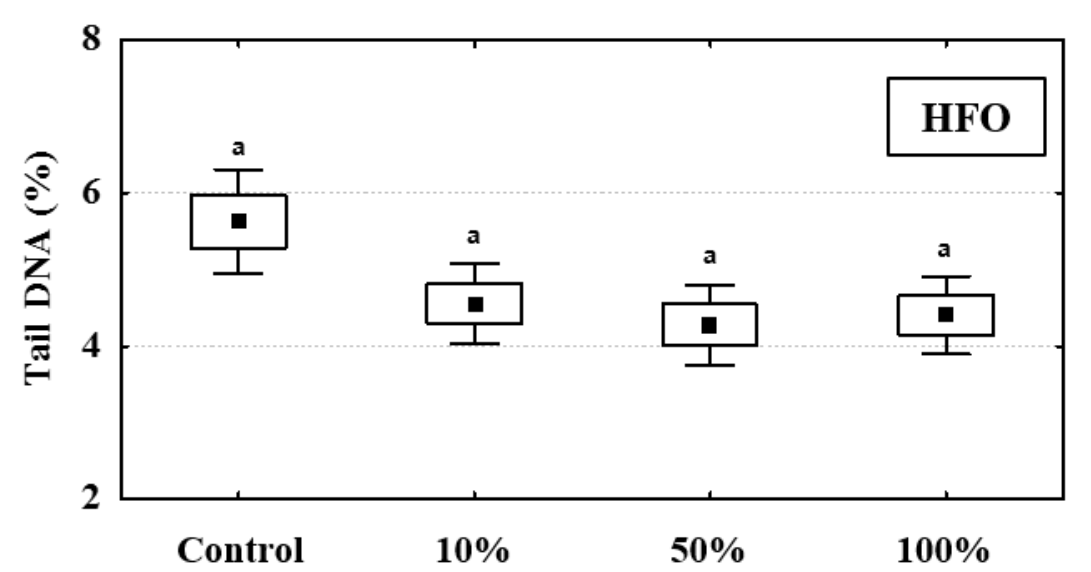




\section{FIGURE 7}
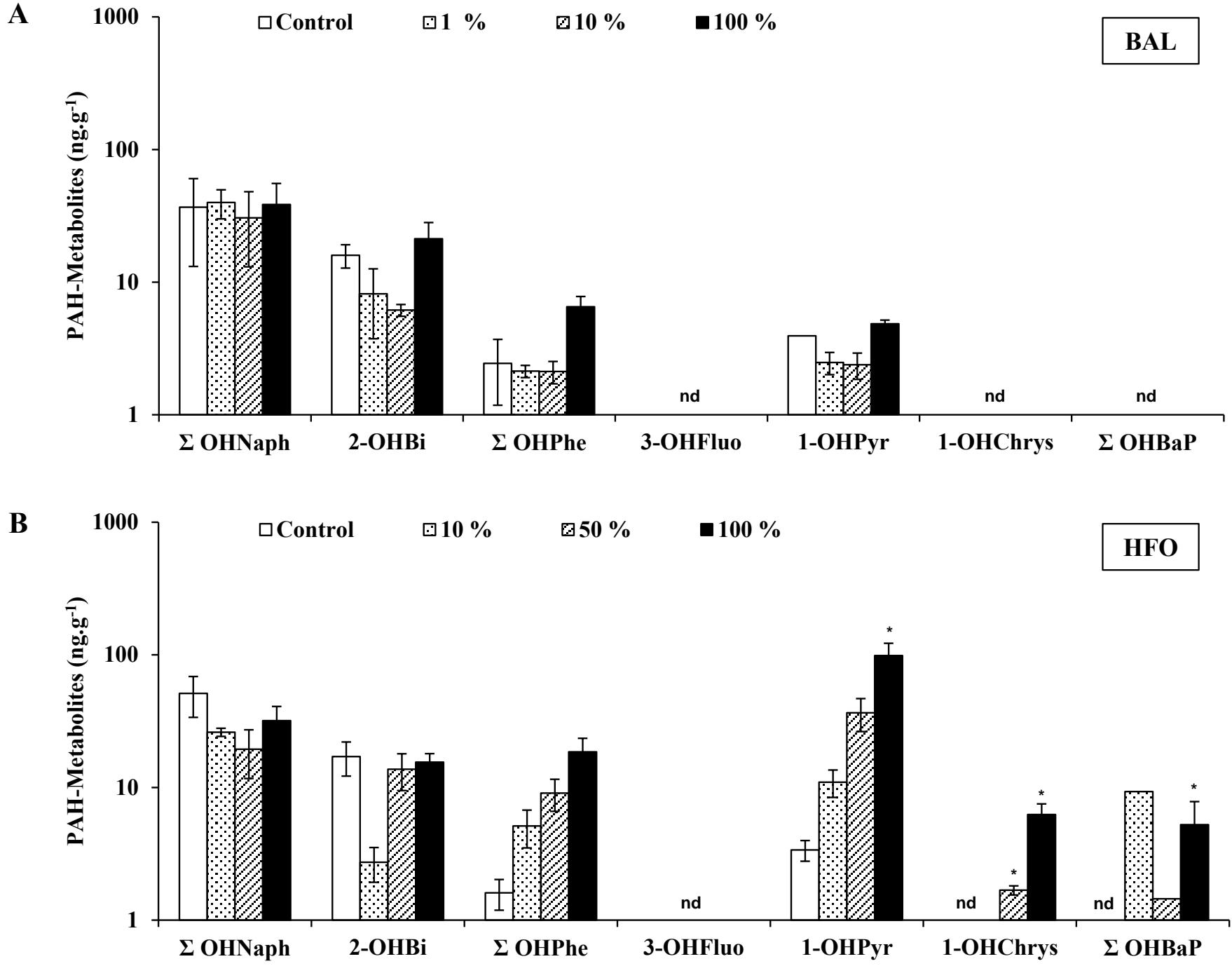


\section{GRAPHICAL ABSTRACT}

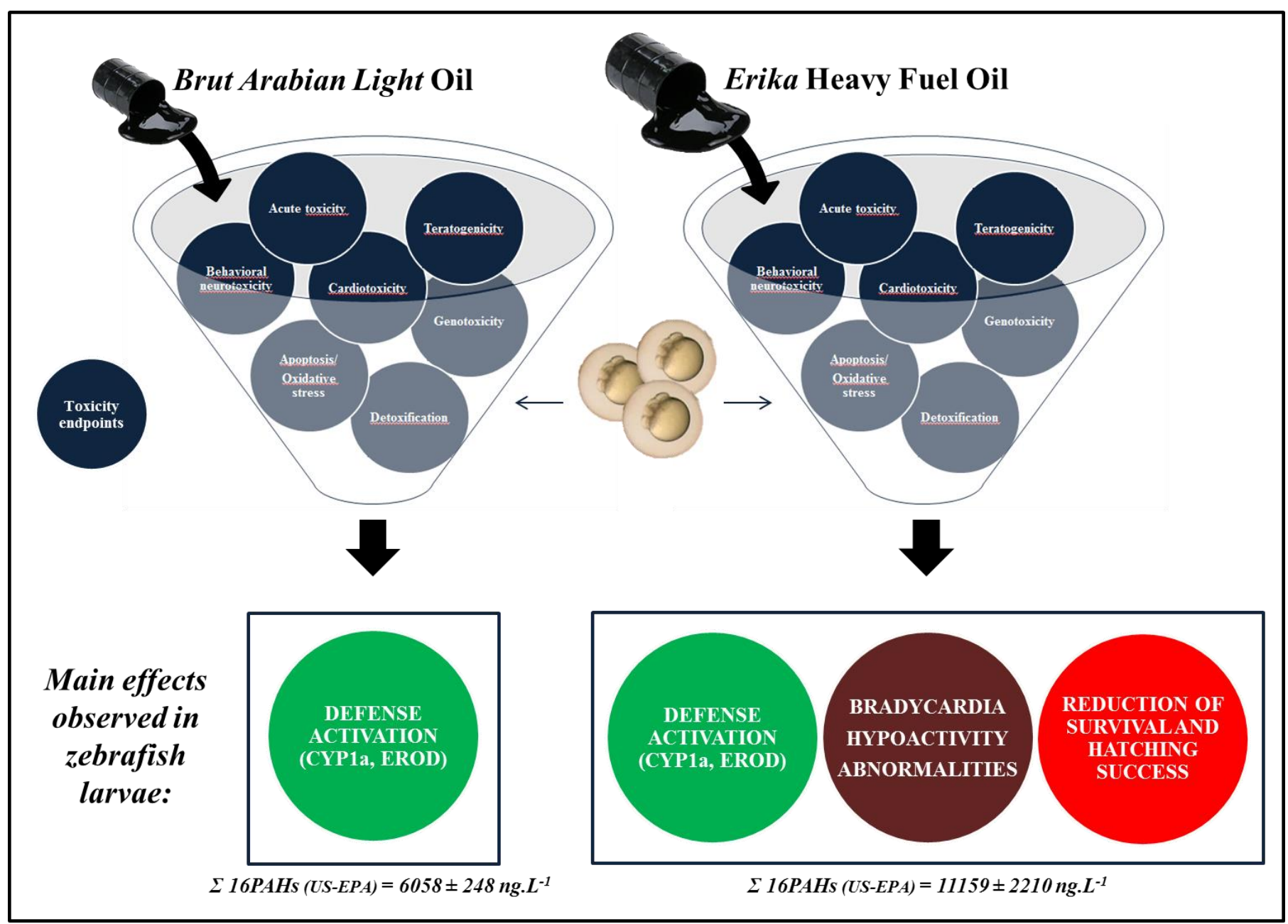

